\title{
Radiative transfer modeling with BGC-Argo float data in the Mediterranean Sea
}

\author{
Elena Terzić ${ }^{1}$, Arnau Miró ${ }^{1,2}$, Paolo Lazzari ${ }^{1}$, Emanuele Organelli $^{3}$, and Fabrizio D’Ortenzio ${ }^{4}$ \\ ${ }^{1}$ National Institute of Oceanography and Applied Geophysics - OGS Trieste, Italy \\ ${ }^{2}$ Barcelona Supercomputing Center (BSC), Spain \\ ${ }^{3}$ National Research Council (CNR), Institute of Marine Sciences (ISMAR), Via Fosso del Cavaliere 100, 00133 Rome, Italy \\ ${ }^{4}$ Sorbonne Université, CNRS, Laboratoire d'Océanographie de Villefranche, Villefranche-sur-Mer, France
}

Correspondence: Elena Terzić (eterzic@inogs.it)

\begin{abstract}
A radiative transfer model was parameterized and validated using Biogeochemical Argo float data acquired between 2012 and 2017 across the Mediterranean Sea. Fluorescence-derived chlorophyll $a$ concentration, particle backscattering at $700 \mathrm{~nm}$ and fluorescence of colored dissolved organic matter were used to parametrize the light absorption and scattering coefficients of the optically significant water constituents (pure water, non-algal particles, colored dissolved organic matter and phytoplankton). The model was validated with in-situ downwelling irradiance profiles and irradiance-derived apparent optical properties from satellite data, such as the diffuse attenuation coefficients and remote sensing reflectance. To the authors' knowledge, this is the first time that a three-platform comparison of such kind is performed between model, floats and satellites. Results showed that by using regional parameterizations that are not only related to chlorophyll concentration and vertical distribution, the model was able to capture a more accurate spectral response in the examined wavelength range compared
\end{abstract} to chlorophyll-related (or Case 1) optical models. When using alternative models that incorporated also measurements of colored dissolved organic matter fluorescence or particulate optical backscattering, the model skill increased at all examined wavelengths. A series of upgrades, such as the inclusion of temperature and salinity data for the modification of the pure water absorption spectra, a refined pure water absorption model, as well as the correction of regional algorithms that had overestimated the pure water contribution in the blue, all contributed to improve the model performance. Finally, using a multi-spectral optical configuration enabled to estimate also the relative contribution of separate water constituents in the examined spectral range. Simulations including non-algal particles and colored dissolved organic matter performed up to $60 \%$ and $76 \%$ better than when considering the optical properties of pure seawater alone. Moreover, a simulation including phytoplankton absorption resulted in an error reduction of up to $43 \%$, especially at $412 \mathrm{~nm}$ and with a more uniform response at the wavelengths considered. Such studies can therefore also tackle the bio-optically anomalous nature of the Mediterranean Sea, and show that non-chlorophyll-related constituents (i.e. non-algal particles and colored dissolved organic matter) can substantially modulate the underwater light field in the blue. 
https://doi.org/10.5194/bg-2020-473

Preprint. Discussion started: 14 January 2021

(c) Author(s) 2021. CC BY 4.0 License.

(c) (i)

\section{Introduction}

Most ecological models, notwithstanding their increasing spatial resolutions, shorter computational times and improved biological complexity, still employ an oversimplified methodology for optical calculations, usually to predict photosynthetically available light without considering its spectral dependency. Biogeochemical models need to improve their prediction capabilities on marine biogeochemical processes such as chlorophyll concentration, phytoplankton biomass, primary productivity. To achieve this, the implementation of multi- of hyperspectral optical modelling solutions remains essential, also in order to follow up with the pace of such approaches already adopted in remote sensing and in-situ platforms. A link between radiometric quantities and biogeochemical variables can be thus established with a more rigorous description of in-water optical properties through their absorption and scattering fingerprints (Dutkiewicz et al., 2015; Mobley et al., 2015; Gregg and Rousseaux, 2016, 2017).

The Mediterranean Sea has been defined as a bio-optically anomalous region (Gitelson et al., 1996; Bricaud et al., 2002; D’Ortenzio et al., 2002; Corsini et al., 2002; Morel et al., 2007a; Lee and Hu, 2006; Morel and Gentili, 2009; Loisel et al., 2011; Volpe et al., 2007; Organelli et al., 2017b), so that global empirical algorithms, both for satellite remote sensing as well as in-situ applications, are not accurate. Mediterranean waters were with the adoption of global relationships generally observed as "greener" than what would have been expected in terms of the measured, usually low chlorophyll $a$ concentration content (Claustre et al., 2002; Morel and Gentili, 2009).

Among the possible causes for such phenomena could be:

- phytoplankton community structure (cell size, pigment packaging, pigment composition, photophysiology), which can affect phytoplankton absorption $\left(a_{\phi}\right)$ and particle backscattering signal $\left(b_{b p}\right)$;

- excess/deficit of non-algal (biogenic or mineral) particles such as Saharan dust (influencing $a_{N A P}$ and $b_{b p}$ );

- excess/deficit of colored dissolved organic matter (CDOM), influencing $a_{C D O M}$;

either separately, or as a combination of several factors.

In the past decade, the development of new technologies for the acquisition and analysis of bio-optical variables has brought new insights and objects of study, such as CDOM dynamics, size and composition of algal communities, absorption by phytoplankton $\left(a_{\phi}\right)$ and non-algal particles $\left(a_{N A P}\right)$ and particle backscattering $\left(b_{b p}\right)$. Since 2012, a large array of autonomous Biogeochemical-Argo (BGC-Argo) floats has been deployed, measuring a whole set of bio-optical and biogeochemical variables (IOCCG, 2011), which could fill the gap between sample acquisitions and remote sensing measurements. With their high vertical resolution profiles, BGC-Argo floats can serve as an additional tool for tackling the bio-optically anomalous nature of the Mediterranean Sea, also due to their high spatial coverage (Organelli et al., 2017b).

For this reason, an analysis was hereby carried out to show the possibility of using a large array of BGC-Argo float measurements both for a radiative transfer model set-up, as well as for validation purposes. More specifically, profiles of bio-optical and biogeochemical parameters (i.e. fluorescence-derived chlorophyll $a$ concentration (Chl), particle backscattering at $700 \mathrm{~nm}$ $\left(b_{b p}(700)\right)$ and CDOM fluorescence (fDOM)) were used for inherent optical properties (IOP) parameterizations, testing several 
https://doi.org/10.5194/bg-2020-473

Preprint. Discussion started: 14 January 2021

(c) Author(s) 2021. CC BY 4.0 License.

(c) (i)

55 regionally adopted algorithms for $a_{\phi}, a_{C D O M}, a_{N A P}$ and particle scattering $b_{p}$. Radiometric measurements were, on the other hand, used for model validation.

In Section 2, the methods applied in the study are described. Section 3 highlights results and discusses them according to the scope of the analysis. In Section 4 conclusions are drawn, along with the possible directions in the future.

\section{Methods}

\section{$60 \quad 2.1$ BGC-Argo Data Set}

The BGC-Argo data set used in this work is comprised of 39 floats operating between 2012 and 2017, Fig.1. The total number of profiles containing $\mathrm{Chl}$ measurements reaches 5092, however for the sake of the analysis completeness, a few requirements needed to be met. Firstly, only profiles containing the whole suite of following variables were considered, i.e. temperature (T), salinity (S), chlorophyll $a(\mathrm{Chl})$, particle backscattering at $700 \mathrm{~mm}\left(b_{b p}(700)\right)$, fluorescent component of colored dissolved organic matter (fDOM) and downward planar irradiance at 380, 412 and $490 \mathrm{~nm}\left(E_{d}(\lambda)\right)$. Profiles lacking at least one of the required variables were excluded from further calculations (2112). Then, only profiles acquired between 10.00 and 14:00 local time were considered in order to obtain radiometric measurements at lower solar zenith angles, thus removing additional 423 profiles. The total number of profiles left for the analysis was 2557.

The quality control (QC) procedure of radiometric data follows the steps described in Organelli et al. (2016b), whereas the $\mathrm{Chl}$ and $b_{b p}(700)$ QC protocols are found in Schmechtig et al. (2014) and Schmechtig et al. (2018) respectively. Profiles of all variables were uniformly interpolated on a 1 meter grid, starting at $0.5 \mathrm{~m}$. As light is one of the key mechanisms controlling the deep chlorophyll maximum depth (DCM) (Mignot et al., 2014; Cullen, 2015), the choice of the maximum depth range corresponds to the maximum DCM values in the Eastern Mediterranean, i.e. up to $120 \mathrm{~m}$ (Christaki et al., 2001). Therefore, additional 374 profiles were discarded that had depths shallower than $150 \mathrm{~m}$. For a successful calculation of the depth derivative of radiometric profiles, i.e. $K_{d}$, with a non-linear fit of an exponential function with the least squares method, further conditions needed to be met: the first depth measurement of $E_{d}$ had to be shallower than $1 \mathrm{~m}$ (thus discarding 131 profiles) and the number of $E_{d}$ measurements within the first 10 meters had to be at least 5, which discarded another 767 profiles. Moreover, a condition of less than $30 \%$ difference between modelled and computed $E_{d}$ values was thus added which resulted in 147 profiles less. After applying all the QC procedures, the final number of useful profiles for this work resulted in 1138, spatially distributed as in Fig.2.

In order to remove spikes and negative values, all variables except $\mathrm{T}$ and $\mathrm{S}$ were further corrected by applying a 5-point median filter, followed by a 7-point running mean. Negative values were assigned to zero. The fact that this QC procedure in the case of $b_{b p}(700)$ might remove positive spikes, which could be indicators of larger aggregates (Briggs et al., 2011), goes beyond the scope of the present study. 
https://doi.org/10.5194/bg-2020-473

Preprint. Discussion started: 14 January 2021

(c) Author(s) 2021. CC BY 4.0 License.

(c) (i)

\subsection{In-water Radiative Transfer Model}

The irradiance distribution along the water column was parameterized into three streams (Dutkiewicz et al., 2015; Gregg and Rousseaux, 2016): the direct $\left(E_{d i r}\right)$ and diffuse $\left(E_{d i f}\right)$ downward irradiance components and the upwelling diffuse irradiance $\left(E_{u}\right)$. The downward planar irradiance is equivalent to the sum of the two downward streams $\left(E_{d}=E_{d i r}+E_{d i f}\right)$. The light spectrum was discretized into $25 \mathrm{~nm}$ bands covering the range between 350 and $700 \mathrm{~nm}$. For each band, $E_{d i r}(\lambda, z), E_{d i f}(\lambda, z)$ and $E_{u}(\lambda, z)$ were solved as a system of three equations:

$$
\begin{aligned}
\frac{d E_{d i r}(\lambda, z)}{d z} & =-C_{d}(\lambda, z) E_{d i r}(\lambda, z), \\
\frac{d E_{d i f}(\lambda, z)}{d z} & =-C_{s}(\lambda, z) E_{d i f}(\lambda, z)+B_{u}(\lambda, z) E_{u}(\lambda, z)+F_{d}(\lambda, z) E_{d i r}(\lambda, z), \\
\frac{d E_{u}(\lambda, z)}{d z} & =+C_{u}(\lambda, z) E_{u}(\lambda, z)-B_{s}(\lambda, z) E_{d i f}(\lambda, z)-B_{d}(\lambda, z) E_{d i r}(\lambda, z),
\end{aligned}
$$

where $z$ is the depth, $C$ are the attenuation factors, and $B$ and $F$ the backward and forward scattering factors respectively. The attenuation factors $C$ were calculated as the sum of absorption $(a)$ and scattering $(b)$ coefficients normalized over cosines:

$$
\begin{aligned}
C_{d}(\lambda, z) & =\frac{a(\lambda, z)+b(\lambda, z)}{\mu_{d}}, \\
C_{s}(\lambda, z) & =\frac{a(\lambda, z)+r_{s} b_{b}(\lambda, z)}{\mu_{s}}, \\
C_{u}(\lambda, z) & =\frac{a(\lambda, z)+r_{u} b_{b}(\lambda, z)}{\mu_{u}},
\end{aligned}
$$

with absorption and scattering coefficients defined as a linear combination of separate water constituents:

$$
a(\lambda, z)=a_{w}(\lambda, z)+a_{N A P}(\lambda, z)+a_{C D O M}(\lambda, z)+a_{\phi}(\lambda, z)
$$

$b(\lambda, z)=b_{w}(\lambda, z)+b_{p}(\lambda, z)$

Different IOP models to determine $a$ and $b$ are further presented in Section 2.3.

In the three-stream approach, the shape factors were considered constant $r_{s}=1.5, r_{u}=3.0$, as well as the average cosines $\mu_{s}=0.83$ and $\mu_{u}=0.4$ Aas (1987), whilst $\mu_{d}=\cos \left(\theta_{d}^{w}\right)$ where $\theta_{d}^{w}$ denotes the solar zenith angle corrected with water refraction index. Scattering factors were similarly defined:

$$
\begin{aligned}
B_{d}(\lambda, z) & =\frac{b_{b}(\lambda, z)}{\mu_{d}}, \\
B_{s}(\lambda, z) & =\frac{r_{s} b_{b}(\lambda, z)}{\mu_{s}}, \\
B_{u}(\lambda, z) & =\frac{r_{u} b_{b}(\lambda, z)}{\mu_{u}}, \\
F_{d}(\lambda, z) & =\frac{\left(1-b_{b}^{\prime}\right) b(\lambda, z)}{\mu_{d}},
\end{aligned}
$$

where $b_{b}^{\prime}$ is the ratio of backscattering $\left(b_{b}\right)$ to total scattering $(b)$.

Solving the in-water radiative transfer model requires three boundary conditions, one for each stream. $E_{d i r}\left(\lambda, 0^{-}\right)$and $E_{d i f}\left(\lambda, 0^{-}\right)$were derived from the multi-spectral atmospheric radiative transfer model OASIM (Gregg and Casey, 2009), 
https://doi.org/10.5194/bg-2020-473

Preprint. Discussion started: 14 January 2021

(c) Author(s) 2021. CC BY 4.0 License.

(c) (i)

Discussions

specifically validated with the surface irradiance values from the same BGC-Argo data set in the Mediterranean Sea (in this special issue; Lazzari et al., 2020). The boundary conditions for the upward component were set as $E_{u}(\lambda, \infty)=0$. The equations were discretized along depth using the same resolution of the BGC-Argo data and integrated numerically following the methodology described in Dutkiewicz et al. (2015).

\subsection{IOP models}

The in-water radiative transfer analysis comprised of six bigger clusters of IOP simulations, as reported below. The aim of these tests was to show that the model does accurately take into consideration the spectral response based on the selection of appropriate IOPs (both absorption and scattering) and thus correctly resolves the radiative transfer equations. In the following subsections, separate groups of IOP models are described in more detail, along with the upgrades that were tested.

1. Pure water absorption and scattering $\left(a_{w}, b_{w}\right)$

2. 1. + NAP absorption $\left(a_{N A P}\right)$

3. 1. + CDOM absorption $\left(a_{C D O M}\right)$

4. 1. + PFT absorption $\left(a_{\phi}\right)$

5. 1. + particle scattering $\left(b_{p}\right)$

6. 1. $+a_{N A P}+a_{C D O M}+a_{\phi}+b_{p}$

Most models that link biogeochemical quantities with IOPs are assessed for Case 1 water optical types that can be defined as water bodies for which the inherent optical properties (of CDOM and NAP) co-vary with phytoplankton and hence with Chl concentration (Morel and Prieur, 1977). Even though such empirical relationships can be quite useful for parameter estimations, there exists the tendency to oversimplify the optical response of a generally complex biogeochemical environment, as thoroughly discussed in Mobley et al. (2004). Hence, one of the scopes of this paper was to try to compare Case 1 water types with alternative parameterizations that considered additional biogeochemical variables and are described in the following subsections. The depth variability of adopted IOP models followed the eq.13:

$135 \operatorname{IOP}(\lambda, z)=\operatorname{IOP}(\lambda) \frac{X(z)}{\max (X(z))}$,

where $X(z)$ denotes the value of the BGC-Argo variable considered at depth $z$.

Simulation results were verified in two different ways. Firstly, modelled irradiance profiles were matched-up with measured $E_{d}$ profiles at all 3 available wavelengths within the upper $150 \mathrm{~m}$ of depth. Secondly, diffuse attenuation coefficients of downward planar irradiances $\left(K_{d}\right)$ for the first optical depths (i.e. the depth range for which the light at a specific wavelength attenuates e-fold) were calculated for both modelled and measured profiles. $K_{d}$ as an apparent optical property (AOP) does 
https://doi.org/10.5194/bg-2020-473

Preprint. Discussion started: 14 January 2021

(c) Author(s) 2021. CC BY 4.0 License.

(c) (i)

have the advantage to convey more information on IOPs and to a certain extent remove the impact of the external environment's variability (change in sun location, cloud cover, or surface waves, Mobley et al. 2010). This is however present to some extent, despite the quality-control procedure introduced by Organelli et al. (2016b). Moreover, at $490 \mathrm{~nm}$ it is possible to make a 3-platform comparison including model, float and remote sensing data, which is further elucidated in Section 2.4.

\subsubsection{Pure water absorption and scattering}

The original in-water modelling configuration, described in Gregg and Rousseaux (2016), resolves a pure water absorption spectra based on data from various sources, as reported therein. However, the UV and blue part of the visible spectrum, i.e. from 250 to $550 \mathrm{~nm}$, was improved also with more recent spectrophotometric measurements by Mason et al. (2016), which introduced lower values compared to the findings of Smith and Baker (1981); Morel et al. (2007b); Pope and Fry (1997); Lee et al. (2015). Moreover, pure water absorption was accounted also for the influence on seawater optical properties of $\mathrm{T}$ and $\mathrm{S}$ according to Sullivan et al. (2006). The original values for pure water scattering from Smith and Baker (1981) and Morel et al. (2007a) were further upgraded by calculating values based on the method described by Zhang et al. (2009), thereby accounting for the contribution of $\mathrm{T}$ and $\mathrm{S}$. The backscattering-to-total scattering ratio for water is kept as 0.5 as in Gregg and Rousseaux (2016), assuming an isotropic scattering regime.

\subsubsection{Non-algal particles (NAP) absorption}

The non-algal particles are defined as a composite of living organic particles, such as bacteria, zooplankton, detrital organic matter, and suspended inorganic particles (Mobley et al., 2010). The absorption spectrum, despite its heterogeneous biogeochemical composition, follows an exponentially decreasing shape from UV to the red part of the spectrum:

$a_{N A P}(\lambda)=a_{N A P}\left(\lambda_{r e f}\right) e^{-S_{N A P}\left(\lambda-\lambda_{r e f}\right)}$

The absorption at the reference wavelength, $a_{N A P}\left(\lambda_{r e f}\right)$, can be estimated in two ways: either as a function of Chl (a Case 1 optical water type - see eq. 4 in Bricaud et al., 2010), or by considering the range of values measured in the Mediterranean Sea, i.e. between 0.0087 and $0.8 \mathrm{~m}^{-1}$ (Babin et al., 2003), with the higher values corresponding to highly turbid waters. The slope $S_{N A P}$ varies from 0.0178 and $0.0104 \mathrm{~nm}^{-1}$, with a mean value of $0.0129 \mathrm{~nm}^{-1}$, Babin et al. (2003). It should be noted however that the data collected in the work were from coastal regions, therefore the minimum values could also overestimate the contribution of $a_{N A P}$ compared to the open ocean. To better reproduce the vertical distribution of NAP, different profile shapes are considered when estimating model IOPs: Case 1 optical types assume a co-variability with Chl, and additional tests were performed by considering $b_{b p}(700)$ as a better proxy for non-algal particle vertical distribution, as shown in eq.13.

$b_{b p}(700)$ can be used as a proxy for POC concentration, as well as for the total suspended matter or phytoplankton carbon (see Organelli et al., 2017a and references therein). However, the separation of organic and inorganic fractions is presently not possible and also beyond the scope of the work. A hypothesis was thus placed to quantify the model's skill when considering $b_{b p}(700)$ as a better parameter from the BGC-Argo set of measurements in terms of NAP depth variability. 
https://doi.org/10.5194/bg-2020-473

Preprint. Discussion started: 14 January 2021

(c) Author(s) 2021. CC BY 4.0 License.

(c) (i)

\subsubsection{CDOM absorption}

Similarly to $a_{N A P}$, the spectral response of $a_{C D O M}$ is also expressed as a decreasing exponential function:

$a_{C D O M}(\lambda)=a_{C D O M}\left(\lambda_{r e f}\right) e^{-S_{C D O M}\left(\lambda-\lambda_{r e f}\right)}$

$a_{C D O M}\left(\lambda_{\text {ref }}\right)$ can be also estimated as a function of $\mathrm{Chl}$ from a regional Case 1 model presented in Morel and Gentili (2009) and based on spectral coefficients of pure water as measured by Pope and Fry (1997). However, given the substantial modification of the $a_{w}$ absorption spectra in the UV/blue range when following Mason et al. (2016) compared to originally adopted values from Pope and Fry (1997), a set of simulations was tested by subtracting the former $a_{O R I G}(\lambda)$ with the updated one, $a_{w}$, as shown in eq.16. With previous values, $a_{O R I G}(\lambda)$ amounted to a higher water absorption, which would have lead to a significant underestimation of $a_{C D O M}$.

$a_{C D O M}^{\text {corr }}(\lambda)=a_{C D O M}(\lambda)+a_{w}^{O R I G}(\lambda)-a_{w}(\lambda)$

The remaining parameter to estimate was the slope $S_{C D O M}$, which can be taken from Babin et al. (2003) and Organelli et al. (2014), i.e. ranging between 0.015 and $0.02 \mathrm{~nm}^{-1}$, with a mean value of $0.017 \mathrm{~nm}^{-1}$.

As with NAP, the Case 1 model for $a_{C D O M}$ was upgraded by considering the fDOM profile shape instead of Chl.

Following Organelli and Claustre (2019), $a_{C D O M}(380)$ was computed from the BGC-Argo irradiance profile at $380 \mathrm{~nm}$, from which the diffuse attenuation coefficient $K_{d}(380)$ was derived, both for the mixed layer as for the first optical depth. The former was obtained from a potential density threshold value criterion (de Boyer Montégut et al., 2004), whereas the latter corresponds to the e-folding depth at the specific wavelength. $K_{d}(380)$ was then estimated from a non-linear fit with the least squares minimization of an exponential function for both depth ranges, and can be separated into pure water and biogenic components (Morel and Maritorena, 2001):

$K_{d}(\lambda)=K_{w}(\lambda)+K_{b i o}(\lambda)$,

where:

$K_{w}(\lambda)=a_{w}(\lambda)+0.5 b_{w}(\lambda)$

After having subtracted the pure water contribution $K_{w}(380)$ as estimated in Morel and Maritorena (2001) (i.e. 0.0151

$m^{-1}$ ), the remaining item, $K_{b i o}(380)$, serves as a proxy for $a_{C D O M}(380)$. Given the fact that the IOP models used for pure water absorption presented also an upgrade by considering Mason et al. (2016), as well as by introducing a T-S correction for pure water IOPs (Sullivan et al., 2006; Zhang et al., 2009), different tests were tried in order to calculate $K_{w}(380)$ as a function of $a_{w}(380)$ and $b_{w}(380)$ rather than adopting a constant value. The entire $a_{C D O M}$ spectrum is then estimated with the slope range of values as described above, with the depth variability analogous to the fDOM shape. 
https://doi.org/10.5194/bg-2020-473

Preprint. Discussion started: 14 January 2021

(c) Author(s) 2021. CC BY 4.0 License.

(c) (i)

\subsubsection{Phytoplankton absorption}

For phytoplankton Chl-specific absorption spectra, data for seven different algal species of varying size were used (Organelli et al., 2017c). Absorption spectra were obtained for species cultured at the light regime of $100 \mu \mathrm{molphotons} \mathrm{m}^{-2} \mathrm{~s}^{-1}$.

The total phytoplankton absorption is computed as the sum of separate phytoplankton functional types (PFT) spectra $a_{\phi}^{i}(\lambda)$ as shown in eq.19:

205

$a_{\phi}(\lambda, z)=\sum_{i=1}^{6} a_{\phi}^{i}(\lambda) f_{\phi}^{i} \operatorname{Chl}(z)$,

The relative contribution of each PFT to the total $\mathrm{Chl}$ concentration, i.e. $f_{\phi}^{i}(z)$, followed the regional empirical algorithm introduced by Di Cicco et al. (2017), Table 4. For that purpose, 7 algal species were merged into 6 PFTs: Diatoms, Dinoflagellates, Cryptophytes, Green Algae and Prochlorococcus, Prochlorococcus and Synechococcus, Coccolithophores. The relative contribution of Prochlorococcus was divided into 0.5 for the 2 PFTs containing the same species.

Original spectra with a $1 \mathrm{~nm}$ frequency were converted to $25 \mathrm{~nm}$ bins, corresponding to the model spectral resolution.

The regional algorithm of Di Cicco et al. (2017) was validated with an in-situ data for first $50 \mathrm{~m}$, with the majority of samples in the Western Mediterranean. Apart from the spatio-temporal bias inherent to ship-borne measurements with which the relationship was obtained, it is suitable for Chl values in the range between 0.02 and $5.52 \mathrm{mg} \mathrm{m}^{-3}$. Therefore, Chl values higher than $5.52 \mathrm{mg} \mathrm{m}^{-3}$ or lower than $0.02 \mathrm{mg} \mathrm{m}^{-3}$ have been limited to $\mathrm{Chl}=5.52$ and $0.02 \mathrm{mg} \mathrm{m}^{-3}$ respectively.

\subsubsection{Particle scattering}

Unlike the model set-up in Gregg and Rousseaux (2016), the particle scattering $b_{p}$ is resolved as a total sum, and not partitioned into the relative scattering contributions of separate PFTs. Following eq. 14 in Morel et al. (2002), $b_{p}$ is expressed as a function of Chl:

$b_{p}(\lambda, z)=0.416[\operatorname{Chl}(z)]^{0.766} \frac{\lambda}{550}^{\nu}$,

where $\nu=0.5\left[\log _{10}(C h l)-0.3\right]$ if $0.02<\mathrm{Chl}<2 \mathrm{mgm}^{-3}$ and $\nu=0$ if $\mathrm{Chl}>2 \mathrm{mg} \mathrm{m}^{-3} . \nu$ values are between -1 and 0 . Commonly used in earlier models, the value of $\nu=-1$ is derived from Mie theory and is known to be valid only for nonabsorbing particles with a Junge particle size distribution slope of -4 (Mobley et al., 2010). Similarly to the PFT regional algorithm modification, $\nu$ is calculated as if $\mathrm{Chl}$ were equal to $0.02 \mathrm{mg} \mathrm{m}^{-3}$ for values lower than the minimum concentration. Both $\mathrm{Chl}$ and $b_{b p}(700)$ shapes were taken into consideration to account for the depth variability. Alternatively, $b_{b p}(700)$ from BGC-Argo floats can be also used to estimate $b_{p}$. A spectrum of $b_{b p}(\lambda)$ can be obtained from eq.21:

$b_{b p}(\lambda)=b_{b p}\left(\lambda_{o}\right)\left(\frac{\lambda}{\lambda_{o}}\right)^{\eta}$ 
https://doi.org/10.5194/bg-2020-473

Preprint. Discussion started: 14 January 2021

(c) Author(s) 2021. CC BY 4.0 License.

(c) (i)

Discussions

where $\eta$ is a proxy for the slope of the particle size distribution, assuming that the particles are non-absorbing. Lower slope values (around 0 to 1 ) indicate the presence of larger particles and vice-versa. The range of tested values was between 0 to 4 , where the highest slope value agrees with measurements at the BOUSSOLE buoy (Antoine et al., 2011). A mean value of 2 was used according to Organelli et al. (2016a). The relative contribution of back- to total particle scattering can be quantified with a known backscattering ratio $\widetilde{b_{b p}}(\lambda)$ :

$\widetilde{b_{b p}}(\lambda)=\frac{b_{b p}(\lambda)}{b_{p}(\lambda)}$,

in the present set of simulations ranging between 0.2 and $1.5 \%$ (Antoine et al., 2011). The depth variability follows $b_{b p}(700)$ profiles (see eq.13).

\subsection{Remote Sensing Data}

Both AOPs, i.e. remote sensing reflectance and $K_{d}$, can be described as functions of absorption and (back)scattering coefficients (Morel and Gentili, 1993; Gordon, 1989).

In order to compare model data with satellite measurements, the calculation of in-water remote sensing reflectance $R_{r s}^{-}(\lambda)$ was carried out by following:

$R_{r s}^{-}\left(\theta_{o}, \lambda, C h l\right)=\frac{E u(\lambda)}{E d(\lambda)} \frac{1}{Q\left(\theta_{o}, \lambda, C h l\right)}$,

where the calculation of $\mathrm{Q}$, a function of wavelength $\lambda$, Chl, and solar zenith angle $\theta_{o}$, follows the procedure introduced by Morel et al. (2002):

$Q\left(\theta_{o}, \lambda, C h l\right)=Q_{o}\left(\theta_{o}, \lambda, C h l\right)+S_{Q n}(\lambda, C h l)\left[1-\cos \left(\theta_{o}\right)\right]$

Values of $Q_{o}(0, \lambda, C h l)$ and $S_{Q n}(0, \lambda, C h l)$ are interpolated from the look-up Table 2 in Morel et al. (2002). Surface

$245 \mathrm{Chl}$ values were taken from float measurements at the shallowest depth. In case of Chl concentrations below $0.03 \mathrm{mg} \mathrm{m}^{-3}$, $Q_{o}(0, \lambda, C h l)$ and $S_{Q n}(0, \lambda, C h l)$ were taken from the minimum value.

The conversion from in-water to above-water remote sensing reflectance $R_{r s}^{+}$(hereafter $R_{r s}$ ) follows the relationship from Lee et al. (2002):

$R_{r s}=\frac{0.53 R_{r s}^{-}}{1-1.7 R_{r s}^{-}}$

Satellite data were obtained from Copernicus Marine Environment Monitoring Service, i.e. the Ocean Colour Level 3 products, comprising of $R_{r s}(\lambda)$ data at 6 wavelengths: 412,443,490,510,555, $670 \mathrm{~nm}$, as well as of the diffuse attenuation of downwelling irradiance at $490 \mathrm{~nm}, K_{d}(490)$. 
https://doi.org/10.5194/bg-2020-473

Preprint. Discussion started: 14 January 2021

(c) Author(s) 2021. CC BY 4.0 License.

\section{(c) (i)}

Locations of floats were matched-up with daily satellite data of a $1 \mathrm{~km}$ space resolution. 445 points were left for the period corresponding to the simulations considered. Due to a reduced number of matched-up quantities, the values of $R_{r s}(\lambda)$ and $K_{d}(490)$ were spatially aggregated to Western and Eastern Mediterranean basins, and temporally in the form of monthly climatological values.

\section{Results and Discussion}

\subsection{IOP model validation}

In order to verify the improvement of various modelling configurations, simulations were clustered into groups of separate IOPs, each with its own selection of tests and modifications. The model skill was quantified with three statistical parameters (root mean square error or RMSE, bias and Pearson correlation coefficient $r$ ), as shown in the Appendix A, resulting from a point-by-point match-up of modelled and measured downwelling irradiance values for the first 150 meters at 3 wavelengths.

Starting with a pure water IOP model, the updated absorption spectrum in the UV/blue range (Mason et al., 2016) reveals a skill deterioration due to a much lower water absorption in the tested range of the spectrum. Most noticeably at shorter wavelengths, RMSE increases by $0.13,0.08$ and $0.01 \mathrm{~W} \mathrm{~m}^{-2} \mathrm{~nm}^{-1}(29 \%, 16 \%$ and $5 \%$ ) at 380, 412 and $490 \mathrm{~nm}$ respectively compared to the "reference" simulation (i.e. with the pure water absorption spectrum used in Gregg and Rousseaux, 2016). Similarly, bias increases by $0.12,0.04$ and $0.01 \mathrm{~W} \mathrm{~m}^{-2} \mathrm{~nm}^{-1}(29 \%, 18 \%$ and $6 \%)$ compared to the reference configuration. The correlation coefficient $r$ decreases by $0.25,0.10$ and 0.001 (39\%, 15\% and less than 1\%) respectively, Fig.3. The choice of the updated absorption values from Mason et al. (2016) is nonetheless preferred by the methodology improvement, which enabled more accurate measurements of the pure water absorption.

The inclusion of $\mathrm{T}$ and $\mathrm{S}$ data both for absorption (Sullivan et al., 2006) and scattering spectra (Zhang et al., 2009) displays a smaller, however notable improvement in the model's skill. Compared to the simulation with absorption values from Mason et al. (2016), RMSE decreases by $0.03,0.04$ and $0.01 \mathrm{Wm}^{-2} \mathrm{~nm}^{-1}(7 \%, 8 \%$ and $1 \%)$ and the bias by $0.02,0.04$ and 0.01 $W m^{-2} \mathrm{~nm}^{-1}(5 \%, 9 \%$ and $6 \%)$. The last configuration, i.e. with the modification from Mason et al. (2016) and T-S corrected models of $a_{w}$ and $b_{w}$ was therefore chosen for subsequent tests.

A series of tests were performed for $a_{N A P}$ parameterizations, Fig.4. Starting with a Case 1 model that follows the Chl profile shape, the consecutive improvements incorporated the inclusion of $b_{b p}(700)$ depth variability. Moreover, the range of $a_{N A P}(443)$ and $S_{N A P}$ values from Babin et al. (2003) were tested with both $\mathrm{Chl}$ and $b_{b p}(700)$ shapes. Among the tests with a varying range of values $\left(S_{N A P}\right.$ between 0.0104 and 0.0178 , and $a_{N A P}(443)$ between 0.0087 and $0.08 \mathrm{~m}^{-1}$, the latter corresponding to highly turbid waters), the minimum value for $a_{N A P}(443)$ was chosen, assuming that floats are located in open waters with a low or negligible contribution of sediments. The slope $S_{N A P}$ is selected from a mean value of 0.0129 from Babin et al., 2003.

Considering $b_{b p}(700)$ shape instead of $\mathrm{Chl}$ in the Case 1 configuration from Bricaud et al. (2010) significantly increases the skill, especially towards the UV, i.e. RMSE decreases by $0.04,0.04$ and $0.001 \mathrm{~W} \mathrm{~m}^{-2} \mathrm{~nm}^{-1}(12.5 \%, 11.5 \%$ and less than $1 \%)$.

The bias on the other hand decreases by $0.03,0.03$ and $0.01 \mathrm{~W} \mathrm{~m}^{-2} \mathrm{~nm}^{-1}(11 \%, 10 \%$ and $7 \%)$. Shifting towards non-Case-1 
https://doi.org/10.5194/bg-2020-473

Preprint. Discussion started: 14 January 2021

(c) Author(s) 2021. CC BY 4.0 License.

representations, i.e. with the inclusion of the range of values observed in in-situ measurements, gives an overall better match-up statistics, which especially improves when considering the $b_{b p}(700)$ shape, Fig.4. Comparing the $b_{b p}(700)$-shaped model with values from Babin et al. (2003) and the analogous Case 1 model, RMSE decreases by 0.14, $0.11,0.01 \mathrm{Wm}^{-2} \mathrm{~nm}^{-1}(50 \%$, $36 \%$ and $5 \%)$, the bias by $0.13,0.12,0.01 \mathrm{Wm}^{-2} \mathrm{~nm}^{-1}(55 \%, 46 \%$ and $7 \%)$ for the three measured wavelengths respectively. $r$ increases by $0.15(21 \%), 0.08(10 \%)$ and at 490 decreases by $0.01(7 \%)$. Therefore, according to the present data, the highest skill is achieved using the $b_{b p}(700)$ shape with the $a_{N A P}$ model suggested by Babin et al. (2003).

Similarly to NAP simulations, CDOM absorption models were also compared considering three aspects: the Case 1 versus alternative parameterizations, Chl versus fDOM IOP depth variability, and additional spectral corrections due to modifications in the pure water spectrum shown in eq.16. As in $a_{N A P}$, considering shapes alternative to Chl, such as profiles of fDOM, reveals an improvement in the match-up statistics. fDOM-shaped Case 1 model from Morel and Gentili (2009) introduces a RMSE decrease $0.05,0.05$ and $0.001 \mathrm{Wm}^{-2} \mathrm{~nm}^{-1}(20 \%, 19 \%$ and less than $1 \%)$ and a reduction of bias amounting to 0.03 , 0.03, $0.01 \mathrm{Wm}^{-2} \mathrm{~nm}^{-1}(17 \%, 16 \%$ and $8 \%) . r$ increases by $0.10,0.05$ and $0.01(13 \%, 6 \%$ and $1 \%)$, Fig.5. As in Fig.4, the largest impact on the lowering of bias and RMSE values was noticed due to a deviation from Case 1 models. This was achieved by adopting the approach presented in Organelli and Claustre (2019), described in Section 2.3.3, with the difference that the first optical depth range was rather considered as it resulted in a better performance compared to the MLD (not shown). Relative to the fDOM-shaped Case 1 model, the RMSE decreases by $0.06,0.05$ and $0.02 \mathrm{Wm}^{-2} \mathrm{~nm}^{-1}(30 \%, 23 \%$ and $11 \%)$, and the bias lowers by $0.06,0.06$ and $0.02 \mathrm{~W} \mathrm{~m}^{-2} \mathrm{~nm}^{-1}(40 \%, 37 \%$ and 17\%) at 380, 412 and 490 nm respectively. Subsequent simulations result in an upgrade in the calculation of $K_{w}$ : from the original value of $0.0151 \mathrm{~m}^{-1}$ (Morel and Maritorena, 2001), $K_{w}$ was calculated by taking into consideration the T-S corrections for both absorption and scattering values. Moreover, the $a_{C D O M}$ was modified for the spectral correction of $a_{w}$. Compared to the constant $K_{w}$ value simulation, the final configuration resulted in a decrease in RMSE by $0.04,0.04$ and $0.02 \mathrm{Wm}^{-2} \mathrm{~nm}^{-1}(29 \%, 24 \%$ and $13 \%)$ and in a bias decrease by 0.03 , 0.03 and $0.02 \mathrm{~W} \mathrm{~m}^{-2} \mathrm{~nm}^{-1}(34 \%, 30 \%$ and $20 \%)$ for 380, 412 and $490 \mathrm{~nm}$. $r$ increases by $0.05,0.04$ and $0.001(5 \%, 4 \%$ and less than $1 \%$ ).

The contribution of remaining IOPs, phytoplankton absorption $a_{\phi}$ and scattering by particles $b_{p}$, are shown alongside the skill of the chosen models for separate IOP groups described above, Fig.6. The PFT modelling configuration described in Section 2.3.4 resulted in a RMSE decrease by $0.14,0.20$ and $0.07 \mathrm{Wm}^{-2} \mathrm{~nm}^{-1}(33 \%, 44 \%$ and $32 \%)$ and in a bias decrease by $0.15,0.20$ and $0.07 \mathrm{~W} \mathrm{~m}^{-2} \mathrm{~nm}^{-1}(37 \%, 49 \%$ and $41 \%)$. The correlation increased by $0.23,0.17$ and $0.04(34 \%, 22 \%$ and $4 \%$ ). Based on the phytoplankton absorption curves adopted in the model, the highest decrease in RMSE and bias at 412 nm can be explained by the proximity to the chlorophyll $a$ absorption peak in the blue, which can also explain a more uniform spectral change of skill. Moreover, the absorption values of most PFTs (except Cryptophytes and Synechococcus) are similar at 380 and $490 \mathrm{~nm}$, with slightly higher values at $380 \mathrm{~nm}$.

Even though several $b_{p}$ configurations were tested, their impact on the $E_{d}$ match-up was negligible, leading to small differences between simulation results. Given the fact that no upwelling component of irradiance measurements $E_{u}$ is available from BGC-Argo floats, a more in-depth study of most appropriate scattering regimes is left for similar tests with data from multi-spectral platforms as ProVal (Leymarie et al., 2018). The most adequate scattering model was a non-Case 1 type, i.e. 
https://doi.org/10.5194/bg-2020-473

Preprint. Discussion started: 14 January 2021

(c) Author(s) 2021. CC BY 4.0 License.

\section{(c) (i)}

derived from $b_{b p}(700)$ measurements following equations 21 and 22, with a maximum backscattering ratio $\widetilde{b_{b p}}(\lambda)$ of 0.015 and a spectral slope $\eta$ of 3 .

The final modelling configuration results in a RMSE ranging from 0.05 to $0.09 \mathrm{~W} \mathrm{~m}^{-2} \mathrm{~nm}^{-1}$, a negative bias of -0.004 $W m^{-2} \mathrm{~nm}^{-1}$ at $412 \mathrm{~nm}$ and positive values of 0.01 and $0.02 \mathrm{Wm}^{-2} \mathrm{~nm}^{-1}$ at 380 and $490 \mathrm{~nm}$, while $r$ amounts to 0.94 at $380 \mathrm{~nm}$ and 0.95 at 412 and $490 \mathrm{~nm}$, Fig.7. The slope is closest to 1 at $490 \mathrm{~nm}$, with the highest value observed at $380 \mathrm{~nm}$ (1.07), signifying a model overestimation, and lowest slope at $412 \mathrm{~nm}(0.81)$, with model values lower than float measurements.

\subsection{Comparison with in-situ and remote sensing apparent optical properties}

Results were further assessed also in terms of diffuse attenuation coefficients for downwelling irradiance $K_{d}(\lambda)$ and remote sensing reflectance $R_{r s}(\lambda)$. Both AOPs were calculated following methods described in Sections 2.3 and 2.4.

Additionally, for the wavelength $490 \mathrm{~nm}$, a three-platform comparison was possible, i.e. model- and float-derived $K_{d}(490)$ versus satellite data, as shown in Fig.8. The match-up of satellite and float observations amounted to 445 co-located measurements which were spatio-temporally aggregated into climatological months and grouped according to western and eastern basins. Therefore, this data can provide further insight on the IOP selection in a more qualitative way.

Modelled $K_{d}(\lambda)$ coefficients replicated the monthly dynamics conveyed in float-derived values, Fig. 8 . At $380 \mathrm{~nm}$, maximum discrepancy is seen in winter and spring months for western basins, with a largest difference in the month of April, i.e. mean values of 0.13 and $0.10 \mathrm{~m}^{-1}$ for model and data respectively (top figure in Fig.8). Modelled values are higher for the reference configuration than float-derived ones in both regions, which might stem from an overestimation of IOPs. At longer wavelengths the difference diminishes, with good consistency achieved also between the three comparing platforms at $490 \mathrm{~nm}$. However, satellites do not seem to capture highest values in spring for the Western Mediterranean, which is shown from BGC-Argo floats and model results. Overall, $K_{d}(\lambda)$ values are larger for western than eastern basins, as shown in Terzić et al. (2019). Modelling IOPs as functions of available biogeochemical and bio-optical measurements, then, provides a significant reproduction of the zonal gradients. The similar magnitude of error bars from all platforms demonstrates also that the model and data variabilities are close.

A separate set of tests was dedicated to assess the relative contribution of individual IOP groups to the final model performance. In order to investigate the sources of largest differences at $380 \mathrm{~nm}$ shown in Fig.8, a configuration without $a_{N A P}$ was tested in order to qualitatively assess the relative importance of NAP, Fig.9. The choice of the latter simulation display is justified by the fact that the CDOM model selected for the reference configuration follows the derivation of $a_{C D O M}$ from $K_{b i o}(380)$ as shown in Section 2.3.3. In this case, the total absorption in the UV/blue part of the spectrum could be overestimated since the contributions of CDOM and NAP to $K_{d}(380)$ are both comprised. NAP is therefore considered twice, even though the chosen model accounts for the minimal contribution based on Babin et al. (2003). Separate models however follow different depth shapes (from $b_{b p}(700)$ and fDOM respectively), which could also result in having an impact in the final model skill. Nonetheless, with the lack of additional measurements at present, there are no means of separating relative contributions of CDOM and NAP from the $K_{b i o}(380)$ term. 
https://doi.org/10.5194/bg-2020-473

Preprint. Discussion started: 14 January 2021

(c) Author(s) 2021. CC BY 4.0 License.

\section{(c) (i)}

With a diminishing contribution towards longer wavelengths due to an exponentially decreasing spectrum, values of $K_{d}(380)$ display a most notable discrepancy from the reference configuration. Modelled values match measurements also during winter and spring months in the west, Fig.9 (top). Both at 380 and $412 \mathrm{~nm}$ the trend reverses, with an underestimation of modelled values from the month of May to December at 380 and February at $412 \mathrm{~nm}$. Lower model values at west can be seen also at $490 \mathrm{~nm}$, with the largest difference in April. At east, modelled values are closer to measurements at $380 \mathrm{~nm}$ with slightly lower values from models in summer and autumn months. At 412 and $490 \mathrm{~nm}$, modelled values are overall lower than dataderived ones with a good agreement at $490 \mathrm{~nm}$ in April, unlike in the west, where satellite values are still much lower than the modelled ones, Fig.9 (bottom). It could be argued that in the first optical depth range the IOP depth variability plays a smaller role compared to the resulting point-by-point match-up of the entire profiles of $150 \mathrm{~m}$ depth. Hence the removal of NAP resulted in a higher consistency of $K_{d}$ values, especially at shorter wavelengths.

Considering another AOP, however, a different result is obtained. $R_{r s}$ is related to IOPs in such way that is directly proportional to backscattering and inversely proportional to the sum of absorption and backscattering (Morel and Prieur, 1977; Morel and Gentili, 1993).

Looking at model and satellite $R_{r s}$ values as well, the removal of $a_{N A P}$ resulted in an overestimation of modelled $R_{r s}$ values, especially at $412 \mathrm{~nm}$ (up to 60\% - figure not shown). Including a whole set of IOPs, on the other hand, amounted to a smaller difference between modelled and measured $R_{r s}$, with differences decreasing with increasing wavelength, resulting in an overall best agreement between model and satellites, Fig.10. Satellite $R_{r s}$ values are generally higher for eastern basins, especially during summer and autumn, whereas at west the reference configuration shows higher model values compared to satellites at $412 \mathrm{~nm}$ and all months at $443 \mathrm{~nm}$ except from January to March. The range of variability from model data is also larger than from satellites, especially for the Western Mediterranean, Fig.10. Given the lack of upwelling radiometric in-situ measurements, $R_{r s}$ was the only indicator that allowed the assessment of the most adequate scattering model. Using Case 1 from eq. 20 leads to an underestimation of modelled $R_{r s}$ for both west and east, resulting in up to a $60 \%$ discrepancy with satellite values, even when using the $b_{b p}(700)$ shape, and especially during summer months (not shown). The chosen configuration with a slope of 3 is consistent with the range of values from Antoine et al. (2011), reaching best agreement for the Eastern Mediterranean, Fig.10. Exceptions are seen during summer months, when the most adequate slope amounts to 4, and for the west, where modelled and observed values align better with a slope of 2, as in Organelli et al. (2016a) (figure not shown). This result suggests that there are different scattering regimes in play in the two basins, most likely stemming from a different particle size distribution (Antoine et al., 2011), which can provide information on the dominant PFTs (Vidussi et al., 2001; Kostadinov et al., 2009). Lower slope values imply larger particles, which is consistent with the results in the west during usual spring bloom events with larger, microphytoplankton assemblages (20 to $200 \mu \mathrm{m}$ ). On the other hand, higher slope values could suggest smaller particles, consistent with the pico- or nanophytoplankton ( 0.2 to 2 and 2 to $20 \mu \mathrm{m}$ respectively) assemblages usually predominant at the basin level, with the former prevailing especially during spring/summer and the latter during winter. Such conclusions are in line with the previously detected patterns of phytoplankton distribution in Siokou-Frangou et al. (2010) and Uitz et al. (2012), which were confirmed also in Sammartino et al. (2015), Di Cicco et al. (2017) and Navarro et al. (2017). 
https://doi.org/10.5194/bg-2020-473

Preprint. Discussion started: 14 January 2021

(c) Author(s) 2021. CC BY 4.0 License.

\section{(c) (i)}

Additional checks were performed by switching off absorption spectra of separate components, which conveyed that the contribution of each IOP results in a complete spectral picture: the exclusion of $a_{C D O M}$ showed a largest impact, amounting to up to $300 \%$ and $200 \%$ difference between modelled and measured $R_{r s}$ at 412 and 443 nm respectively. On the other hand, the exclusion of $b_{b p}$ and $a_{\phi}$ resulted in lower model $R_{r s}$ values, especially for the Western Mediterranean during winter and spring months, amounting to up to $20 \%$ and $45 \%$ respectively (not shown).

\section{Conclusions}

BGC-Argo floats prove to be an essential observing system to further explore the possibility of integrating data in numerical modelling of physical, as well as biogeochemical and optical properties. Due to the high number of profiles with synoptic measurements of physical and bio-optical parameters, it is possible to use the almost complete suite of measured variables (i.e. T, S, Chl, fDOM, $b_{b p}(700)$ and $\left.E_{d}(\lambda)\right)$ to test various state-of-the art parameterizations of absorption and scattering properties of sea water constituents. The current wavelength selection of $E_{d}(\lambda)$ measurements constitutes an ideal tool to explore the part of the spectrum that is least understood, mostly for the contributions from CDOM and NAP. This is particularly true in the Mediterranean Sea, where the blue-to-green reflectance ratio-based algorithms are known to have low performances (Morel and Gentili, 2009) because of the higher-than-expected contribution of CDOM for a given Chl concentration. The major findings of this work can be summarized as follows: the inclusion of $\mathrm{T}$ and $\mathrm{S}$ data is advisory to consider for the small, but significant spectral modulation of seawater compared to pure water, which also improves the model skill. Furthermore, the tests performed on Case 1 IOP models reveal that the inclusion of additional biogeochemical measurements in the IOP parameterizations results in enhanced match-up statistics, both when comparing with irradiance profiles, as well as with in-situ and remote-sensing derived AOPs. The shape of $b_{b p}(700)$ for $a_{N A P}$ variability increases the skill compared to Chl-shaped models by $27 \%$ in the case of RMSE. Moreover, it was demonstrated that the use of fDOM shape and the estimation of $a_{C D O M}(380)$ for CDOM absorption, as well as the spectral correction of the updated $a_{w}$ spectrum, all contribute to an upgrade in CDOM modelling. Partitioning the contributions of NAP and CDOM to the total absorption with additional experiments would be also advantageous, as well as the assessment of relative contributions of different constituents to the total $b_{b p}(700)$ signal, thus separating the organic and inorganic parts. Observations of other biogeochemical parameters, such as oxygen, nitrate and $\mathrm{pH}$, can be possibly integrated with a coupled biogeochemical model. All of these variables are already available on the BGC-Argo float standard configuration (Claustre et al., 2020). This could offer the opportunity, with an existing validation data set, to consider also the phytoplankton ecology and dynamics of separate functional groups. Such work demonstrates the advantages of combining data with numerical models, which can pave way to a better understanding of biogeochemical processes in the examined regions.

The focus of this study is also more on the absorption models rather than scattering due to the lack of $E_{u}$ measurements, which will be possible to account for with the integration of multi-spectral data from platforms like ProVal (Leymarie et al., 2018). This will enable also the calculation of in-situ $R$ and remote-sensing reflectance estimations $R_{r s}$, thus surpassing 
https://doi.org/10.5194/bg-2020-473

Preprint. Discussion started: 14 January 2021

(c) Author(s) 2021. CC BY 4.0 License.

(c) (1)

Discussions

the current limitation of quantifying the skill between $R_{r s}$ satellite data with model values due to the scarcity of satellite observations spatio-temporally co-located with BGC-Argo float profiles, supporting further the three-platform comparisons.

To conclude, the key point raised in this study is that the inclusion of multi-spectral measurements is essential to tackle the proper biogeochemical response, surpassing the most-commonly PAR-related parameterizations of phytoplankton growth.

With the advancement of satellite sensors and their algorithms it would be necessary to make a comparison of radiative transfer models of different degrees of complexity, and perform similar tests with hyperspectral models which are able to solve a full radiative transfer equation resulting in a complete radiance distribution (Mobley and Sundman, 2008).

\section{Appendix A: Statistical Indicators}

The model skill assessment was evaluated with three statistical parameters: bias, root mean square error (RMSE) and the

$B I A S=\frac{1}{n} \sum_{i=1}^{n}\left(x_{i}-y_{i}\right)$

$R M S E=\sqrt{\frac{1}{n} \sum_{i=1}^{n}\left(x_{i}-y_{i}\right)^{2}}$

$r=\frac{\operatorname{cov}(x, y)}{\sigma_{x} \sigma_{y}}$

where

$\operatorname{cov}(x, y)=\frac{\sum_{i=1}^{n}\left(x_{i}-\bar{x}\right)\left(y_{i}-\bar{y}\right)}{n-1}$

$x$ equals $E d(\lambda)$ from the model output and $y$ denotes $E d(\lambda)$ from BGC-Argo floats; $\sigma$ represents the standard deviation of the model/data values.

Author contributions. ET, AM and PL designed the study and the numerical experiments. ET and AM carried them out. PL developed the RT model. AM supported the parallelization of the code. ET and AM performed the model-data comparison. EO performed the quality-control of irradiance profiles, provided the absorption spectra for all 7 phytoplankton species used in this study and contributed to the choice of the bio-optical models to test. FDO provided funding and contributed with floats deployments. ET prepared the manuscript with contributions from all co-authors. All authors contributed to the interpretation of the results.

Competing interests. The authors declare that they have no conflicts of interest. 
https://doi.org/10.5194/bg-2020-473

Preprint. Discussion started: 14 January 2021

(C) Author(s) 2021. CC BY 4.0 License.

(c) (1)

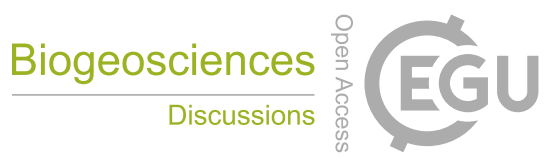

Acknowledgements. This work was performed within the framework of the BIOPTIMOD CMEMS Service Evolution project. CMEMS is

445 implemented by Mercator Ocean International within the framework of a delegation agreement with the European Union. This study was supported by the following research projects funding BGC-Argo floats: NAOS (funded by the Agence Nationale de la Recherche in the frame of the French 'Equipement d'avenir' program, grant agreement ANR J11R107-F), remOcean (funded by the European Research Council, grant agreement 246777), Argo-Italy (funded by the Italian Ministry of Education, University and Research), and the French Bio-Argo program (Bio-Argo France; funded by CNES-TOSCA, LEFE Cyber, and GMMC).

450 The authors would especially like to thank Giorgio Bolzon for his invaluable help and IT support in data management, as well as development of codes and libraries to analyse float and satellite products. Special thanks also to Ilya Chernov (Russian Academy of Science) for his contribution in developing the RT model. 
https://doi.org/10.5194/bg-2020-473

Preprint. Discussion started: 14 January 2021

(c) Author(s) 2021. CC BY 4.0 License.

(c) (i)

\section{References}

Aas, E.: Two-stream irradiance model for deep waters, Applied Optics, 26, 2095-2101, 1987.

Antoine, D., Siegel, D. A., Kostadinov, T., Maritorena, S., Nelson, N. B., Gentili, B., Vellucci, V., and Guillocheau, N.: Variability in optical particle backscattering in contrasting bio-optical oceanic regimes, Limnology and Oceanography, 56, 955-973, 2011.

Babin, M., Stramski, D., Ferrari, G. M., Claustre, H., Bricaud, A., Obolensky, G., and Hoepffner, N.: Variations in the light absorption coefficients of phytoplankton, nonalgal particles, and dissolved organic matter in coastal waters around Europe, Journal of Geophysical Research: Oceans, 108, 2003.

Bricaud, A., Bosc, E., and Antoine, D.: Algal biomass and sea surface temperature in the Mediterranean Basin: Intercomparison of data from various satellite sensors, and implications for primary production estimates, Remote Sensing of Environment, 81, 163-178, 2002.

Bricaud, A., Babin, M., Claustre, H., Ras, J., and Tièche, F.: Light absorption properties and absorption budget of Southeast Pacific waters, Journal of Geophysical Research: Oceans, 115, 2010.

Briggs, N., Perry, M. J., Cetinić, I., Lee, C., D’Asaro, E., Gray, A. M., and Rehm, E.: High-resolution observations of aggregate flux during a sub-polar North Atlantic spring bloom, Deep Sea Research Part I: Oceanographic Research Papers, 58, 1031-1039, 2011.

Christaki, U., Giannakourou, A., Van Wambeke, F., and Grégori, G.: Nanoflagellate predation on auto-and heterotrophic picoplankton in the oligotrophic Mediterranean Sea, Journal of Plankton Research, 23, 1297-1310, 2001.

Claustre, H., Morel, A., Hooker, S., Babin, M., Antoine, D., Oubelkheir, K., Bricaud, A., Leblanc, K., Queguiner, B., and Maritorena, S.: Is desert dust making oligotrophic waters greener?, Geophysical Research Letters, 29, 107-1, 2002.

470 Claustre, H., Johnson, K. S., and Takeshita, Y.: Observing the global ocean with biogeochemical-Argo, Annual Review of Marine Science, $12,23-48,2020$.

Corsini, G., Grasso, R., and Cipollini, P.: Regional bio-optical algorithms for the Alboran Sea from a reflectance model and in situ data, Geophysical research letters, 29, 2002.

Cullen, J. J.: Subsurface Chlorophyll Maximum Layers: Enduring Enigma or Mystery Solved?, Annual Review of Marine Science, 7, 207239, https://doi.org/10.1146/annurev-marine-010213-135111, https://doi.org/10.1146/annurev-marine-010213-135111, 2015.

de Boyer Montégut, C., Madec, G., Fischer, A. S., Lazar, A., and Iudicone, D.: Mixed layer depth over the global ocean: An examination of profile data and a profile-based climatology, Journal of Geophysical Research: Oceans, 109, 2004.

Di Cicco, A., Sammartino, M., Marullo, S., and Santoleri, R.: Regional empirical algorithms for an improved identification of Phytoplankton Functional Types and Size Classes in the Mediterranean Sea using satellite data, Frontiers in Marine Science, 4, $126,2017$.

480 D’Ortenzio, F., Marullo, S., Ragni, M., d'Alcalà, M. R., and Santoleri, R.: Validation of empirical SeaWiFS algorithms for chlorophyll-a retrieval in the Mediterranean Sea: A case study for oligotrophic seas, Remote Sensing of Environment, 82, 79-94, 2002.

Dutkiewicz, S., Hickman, A. E., Jahn, O., Gregg, W. W., Mouw, C. B., and Follows, M. J.: Capturing optically important constituents and properties in a marine biogeochemical and ecosystem model, Biogeosciences, 12, 4447-4481, https://doi.org/10.5194/bg-12-4447-2015, https://www.biogeosciences.net/12/4447/2015/, 2015.

Gitelson, A., Karnieli, A., Goldman, N., Yacobi, Y., and Mayo, M.: Chlorophyll estimation in the Southeastern Mediterranean using CZCS images: adaptation of an algorithm and its validation, Journal of Marine Systems, 9, 283-290, 1996.

Gordon, H. R.: Can the Lambert-Beer law be applied to the diffuse attenuation coefficient of ocean water?, Limnology and Oceanography, 34, 1389-1409, 1989. 
https://doi.org/10.5194/bg-2020-473

Preprint. Discussion started: 14 January 2021

(c) Author(s) 2021. CC BY 4.0 License.

(c) (i)

Gregg, W. W. and Casey, N. W.: Skill assessment of a spectral ocean-atmosphere radiative model, Journal of Marine Systems, 76, 49-63, 2009.

Gregg, W. W. and Rousseaux, C. S.: Directional and spectral irradiance in ocean models: effects on simulated global phytoplankton, nutrients, and primary production, Frontiers in Marine Science, 3, 240, 2016.

Gregg, W. W. and Rousseaux, C. S.: Simulating PACE global ocean radiances, Frontiers in Marine Science, 4, $60,2017$.

IOCCG: Bio-Optical Sensors on Argo Floats, vol. No. 11 of Reports of the International Ocean Colour Coordinating Group, IOCCG, Dartmouth, Canada, http://www.ioccg.org/reports/IOCCG_Report11.pdf, 2011.

Kostadinov, T., Siegel, D., and Maritorena, S.: Retrieval of the particle size distribution from satellite ocean color observations, Journal of Geophysical Research: Oceans, 114, 2009.

Lazzari, P., Salon, S., Terzić, E., Gregg, W. W., D’Ortenzio, F., Vellucci, V., Organelli, E., and Antoine, D.: Assessment of the spectral downward irradiance at the surface of the Mediterranean Sea using the OASIM ocean-atmosphere radiative model, Ocean Science Discussions, 2020, 1-39, https://doi.org/10.5194/os-2020-108, https://os.copernicus.org/preprints/os-2020-108/, 2020.

Lee, Z. and Hu, C.: Global distribution of Case-1 waters: An analysis from SeaWiFS measurements, Remote Sensing of Environment, 101, 270-276, 2006.

Lee, Z., Carder, K. L., and Arnone, R. A.: Deriving inherent optical properties from water color: a multiband quasi-analytical algorithm for optically deep waters, Applied Optics, 41, 5755, https://doi.org/10.1364/AO.41.005755, 2002.

Lee, Z., Wei, J., Voss, K., Lewis, M., Bricaud, A., and Huot, Y.: Hyperspectral absorption coefficient of "pure" seawater in the range of 350-550 nm inverted from remote sensing reflectance, Applied Optics, 54, 546-558, 2015.

Leymarie, E., Penkerc'h, C., Vellucci, V., Lerebourg, C., Antoine, D., Boss, E., Lewis, M. R., d'Ortenzio, F., and Claustre, H.: ProVal: A new autonomous profiling float for high quality radiometric measurements, Frontiers in Marine Science, 5, 437, 2018.

Loisel, H., Vantrepotte, V., Norkvist, K., Meriaux, X., Kheireddine, M., Ras, J., Pujo-Pay, M., Combet, Y., Leblanc, K., Dall'Olmo, G., et al.: Characterization of the bio-optical anomaly and diurnal variability of particulate matter, as seen from scattering and backscattering coefficients, in ultra-oligotrophic eddies of the Mediterranean Sea, Biogeosciences, 8, 3295-3317, 2011.

Mason, J. D., Cone, M. T., and Fry, E. S.: Ultraviolet (250-550 nm) absorption spectrum of pure water, Applied Optics, 55, 7163, https://doi.org/10.1364/AO.55.007163, https://www.osapublishing.org/abstract.cfm?URI=ao-55-25-7163, 2016.

Mignot, A., Claustre, H., Uitz, J., Poteau, A., d'Ortenzio, F., and Xing, X.: Understanding the seasonal dynamics of phytoplankton biomass and the deep chlorophyll maximum in oligotrophic environments: A Bio-Argo float investigation, Global Biogeochemical Cycles, 28, 856-876, 2014.

Mobley, C., Boss, E., and Roesler, C.: Ocean optics web book, URL http://www. oceanopticsbook. info, 2010.

Mobley, C. D. and Sundman, L. K.: HYDROLIGHT 5 ECOLIGHT 5, Sequoia Scientific Inc, 2008.

Mobley, C. D., Stramski, D., Paul Bissett, W., and Boss, E.: Optical modeling of ocean waters: Is the case 1-case 2 classification still useful?, Oceanography, 17, 60, 2004.

Mobley, C. D., Chai, F., Xiu, P., and Sundman, L. K.: Impact of improved light calculations on predicted phytoplankton growth and heating in an idealized upwelling-downwelling channel geometry, Journal of Geophysical Research: Oceans, 120, 875-892, 2015.

Morel, A. and Gentili, B.: Diffuse reflectance of oceanic waters. II. Bidirectional aspects, Applied Optics, 32, 6864-6879, 1993.

Morel, A. and Gentili, B.: The dissolved yellow substance and the shades of blue in the Mediterranean Sea, Biogeosciences, 6, 2625-2636, https://doi.org/10.5194/bg-6-2625-2009, https://www.biogeosciences.net/6/2625/2009/, 2009. 
https://doi.org/10.5194/bg-2020-473

Preprint. Discussion started: 14 January 2021

(c) Author(s) 2021. CC BY 4.0 License.

(c) (i)

Morel, A. and Maritorena, S.: Bio-optical properties of oceanic waters: A reappraisal, Journal of Geophysical Research: Oceans, 106, 7163$7180,2001$.

Morel, A. and Prieur, L.: Analysis of variations in ocean color 1, Limnology and oceanography, 22, 709-722, 1977.

Morel, A., Antoine, D., and Gentili, B.: Bidirectional reflectance of oceanic waters: accounting for Raman emission and varying particle scattering phase function, Applied Optics, 41, 6289-6306, 2002.

Morel, A., Claustre, H., Antoine, D., and Gentili, B.: Natural variability of bio-optical properties in Case 1 waters: attenuation and reflectance within the visible and near-UV spectral domains, as observed in South Pacific and Mediterranean waters, Biogeosciences Discussions, 4 , 2147-2178, 2007a.

Morel, A., Gentili, B., Claustre, H., Babin, M., Bricaud, A., Ras, J., and Tièche, F.: Optical properties of the "clearest" natural waters, Limnology and Oceanography, 52, 217-229, https://doi.org/10.4319/lo.2007.52.1.0217, http://doi.wiley.com/10.4319/lo.2007.52.1.0217, $2007 \mathrm{~b}$.

Navarro, G., Almaraz, P., Caballero, I., Vázquez, Á., and Huertas, I. E.: Reproduction of spatio-temporal patterns of major mediterranean phytoplankton groups from remote sensing oc-cci data, Frontiers in Marine Science, 4, 246, 2017.

Organelli, E. and Claustre, H.: Small phytoplankton shapes colored dissolved organic matter dynamics in the North Atlantic subtropical gyre, Geophysical Research Letters, 46, 12 183-12 191, 2019.

Organelli, E., Bricaud, A., Antoine, D., and Matsuoka, A.: Seasonal dynamics of light absorption by chromophoric dissolved organic matter (CDOM) in the NW Mediterranean Sea (BOUSSOLE site), Deep Sea Research Part I: Oceanographic Research Papers, 91, 72-85, 2014.

Organelli, E., Bricaud, A., Gentili, B., Antoine, D., and Vellucci, V.: Retrieval of Colored Detrital Matter (CDM) light absorption coefficients in the Mediterranean Sea using field and satellite ocean color radiometry: Evaluation of bio-optical inversion models, Remote Sensing of Environment, 186, 297-310, 2016a.

Organelli, E., Claustre, H., Bricaud, A., Schmechtig, C., Poteau, A., Xing, X., Prieur, L., D’Ortenzio, F., Dall’Olmo, G., and Vellucci, V.: A Novel Near-Real-Time Quality-Control Procedure for Radiometric Profiles Measured by Bio-Argo Floats: Protocols and Performances, Journal of Atmospheric and Oceanic Technology, 33, 937-951, 2016b.

Organelli, E., Barbieux, M., Claustre, H., Schmechtig, C., Poteau, A., Bricaud, A., Boss, E., Briggs, N., Dall’Olmo, G., d’Ortenzio, F., et al.:

550 Two databases derived from BGC-Argo float measurements for marine biogeochemical and bio-optical applications, Earth System Science Data, 9, 861-880, 2017a.

Organelli, E., Claustre, H., Bricaud, A., Barbieux, M., Uitz, J., D’Ortenzio, F., and Dall'Olmo, G.: Bio-optical anomalies in the world's oceans: An investigation on the diffuse attenuation coefficients for downward irradiance derived from Biogeochemical Argo float measurements, Journal of Geophysical Research: Oceans, 122, 3543-3564, 2017b.

Organelli, E., Nuccio, C., Lazzara, L., Uitz, J., Bricaud, A., and Massi, L.: On the discrimination of multiple phytoplankton groups from light absorption spectra of assemblages with mixed taxonomic composition and variable light conditions, Applied Optics, 56, 3952, https://doi.org/10.1364/AO.56.003952, https://www.osapublishing.org/abstract.cfm?URI=ao-56-14-3952, 2017c.

Pope, R. M. and Fry, E. S.: Absorption spectrum (380-700 nm) of pure water II Integrating cavity measurements, Applied Optics, 36, 8710, https://doi.org/10.1364/AO.36.008710, https://www.osapublishing.org/abstract.cfm?URI=ao-36-33-8710, 1997.

560 Sammartino, M., Di Cicco, A., Marullo, S., and Santoleri, R.: Spatio-temporal variability of micro-, nano-and pico-phytoplankton in the Mediterranean Sea from satellite ocean colour data of SeaWiFS, Ocean Science, 11, 759, 2015.

Schmechtig, C., Claustre, H., Poteau, A., and D’Ortenzio, F.: Bio-Argo quality control manual for the Chlorophyll-A concentration, 2014. 
https://doi.org/10.5194/bg-2020-473

Preprint. Discussion started: 14 January 2021

(c) Author(s) 2021. CC BY 4.0 License.

(c) (1)

Schmechtig, C., Poteau, A., Claustre, H., D’Ortenzio, F., Dall'Olmo, G., and Boss, E.: Processing Bio-Argo particle backscattering at the DAC level, 2018.

565 Siokou-Frangou, I., Christaki, U., Mazzocchi, M. G., Montresor, M., Ribera d'Alcalá, M., Vaqué, D., and Zingone, A.: Plankton in the open Mediterranean Sea: a review, Biogeosciences, 7, 1543-1586, https://doi.org/10.5194/bg-7-1543-2010, https://bg.copernicus.org/articles/ 7/1543/2010/, 2010.

Smith, R. C. and Baker, K. S.: Optical properties of the clearest natural waters (200-800 nm), Applied Optics, 20, 177, https://doi.org/10.1364/AO.20.000177, https://www.osapublishing.org/abstract.cfm?URI=ao-20-2-177, 1981.

570 Sullivan, J. M., Twardowski, M. S., Zaneveld, J. R. V., Moore, C. M., Barnard, A. H., Donaghay, P. L., and Rhoades, B.: Hyperspectral temperature and salt dependencies of absorption by water and heavy water in the 400-750 nm spectral range, Applied Optics, 45, 5294, https://doi.org/10.1364/ao.45.005294, https://doi.org/10.1364\%2Fao.45.005294, 2006.

Terzić, E., Lazzari, P., Organelli, E., Solidoro, C., Salon, S., D’Ortenzio, F., and Conan, P.: Merging bio-optical data from BiogeochemicalArgo floats and models in marine biogeochemistry, Biogeosciences, 16, 2527-2542, 2019.

575 Uitz, J., Stramski, D., Gentili, B., D’Ortenzio, F., and Claustre, H.: Estimates of phytoplankton class-specific and total primary production in the Mediterranean Sea from satellite ocean color observations, Global Biogeochemical Cycles, 26, 2012.

Vidussi, F., Claustre, H., Manca, B. B., Luchetta, A., and Marty, J.-C.: Phytoplankton pigment distribution in relation to upper thermocline circulation in the eastern Mediterranean Sea during winter, Journal of Geophysical Research: Oceans, 106, 19939-19956, 2001.

Volpe, G., Santoleri, R., Vellucci, V., d'Alcalà, M. R., Marullo, S., and d'Ortenzio, F.: The colour of the Mediterranean Sea: Global versus regional bio-optical algorithms evaluation and implication for satellite chlorophyll estimates, Remote Sensing of Environment, 107, 625$638,2007$.

Zhang, X., Hu, L., and He, M.-X.: Scattering by pure seawater: effect of salinity, Optics Express, 17, 5698-5710, 2009. 
https://doi.org/10.5194/bg-2020-473

Preprint. Discussion started: 14 January 2021

(c) Author(s) 2021. CC BY 4.0 License.
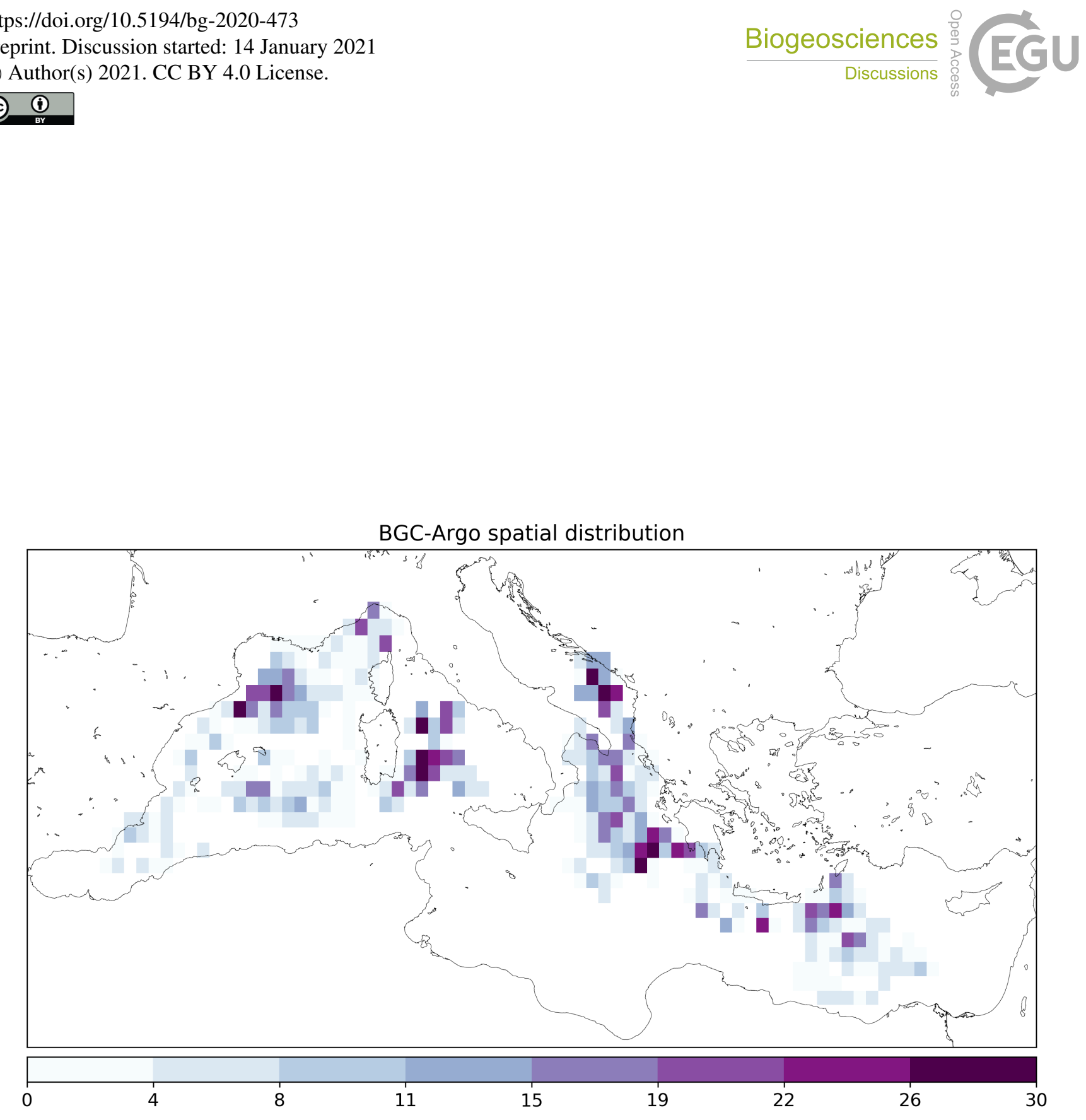

Figure 1. Spatial distribution of the complete data set, prior to additional criteria applied to remove profiles which do not meet computation requirements. 
BGC-Argo removed profiles
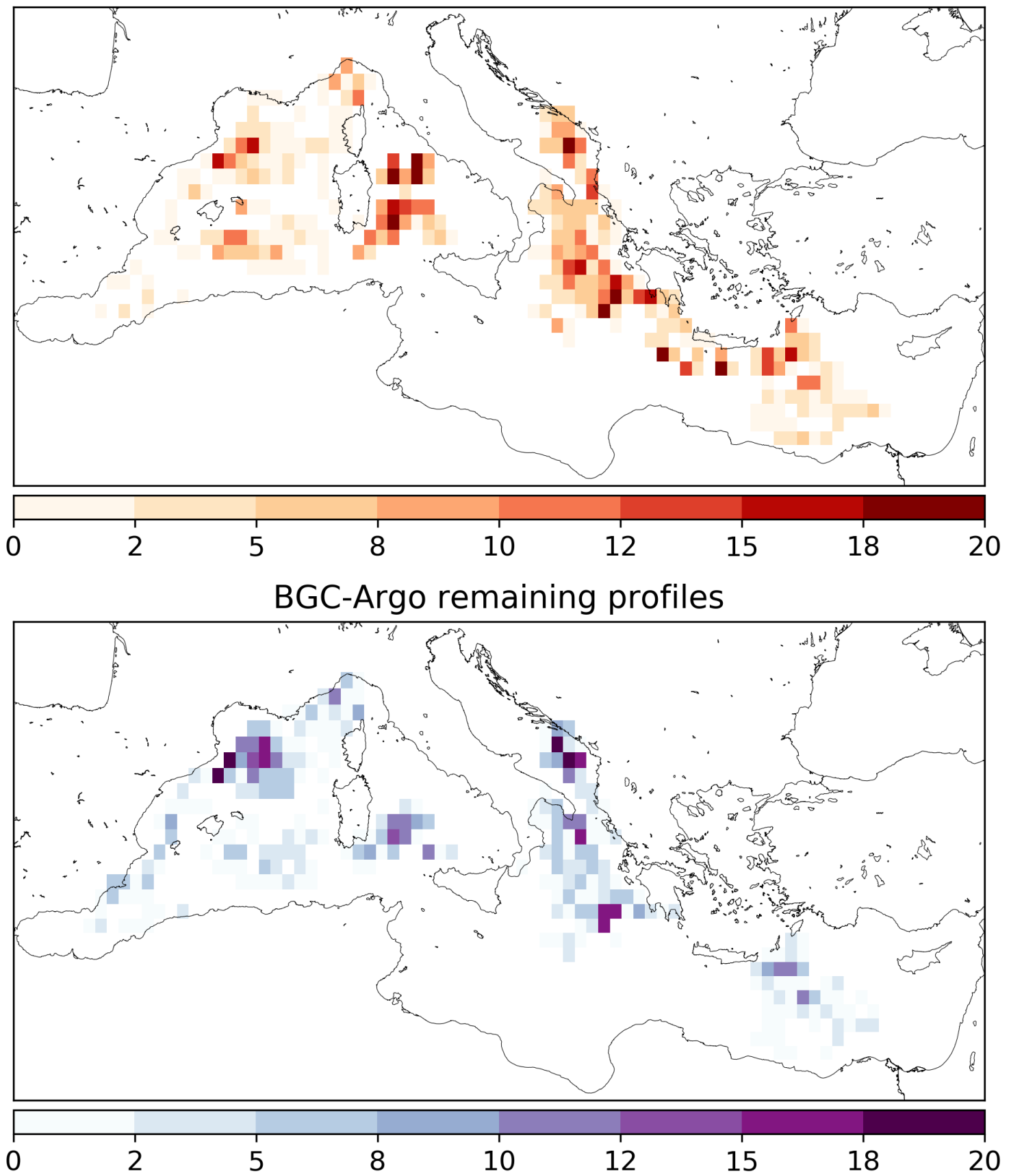

Figure 2. BGC-Argo spatial distribution of removed floats (top figure) and the ones left for the analysis (bottom). 
https://doi.org/10.5194/bg-2020-473

Preprint. Discussion started: 14 January 2021

(c) Author(s) 2021. CC BY 4.0 License.
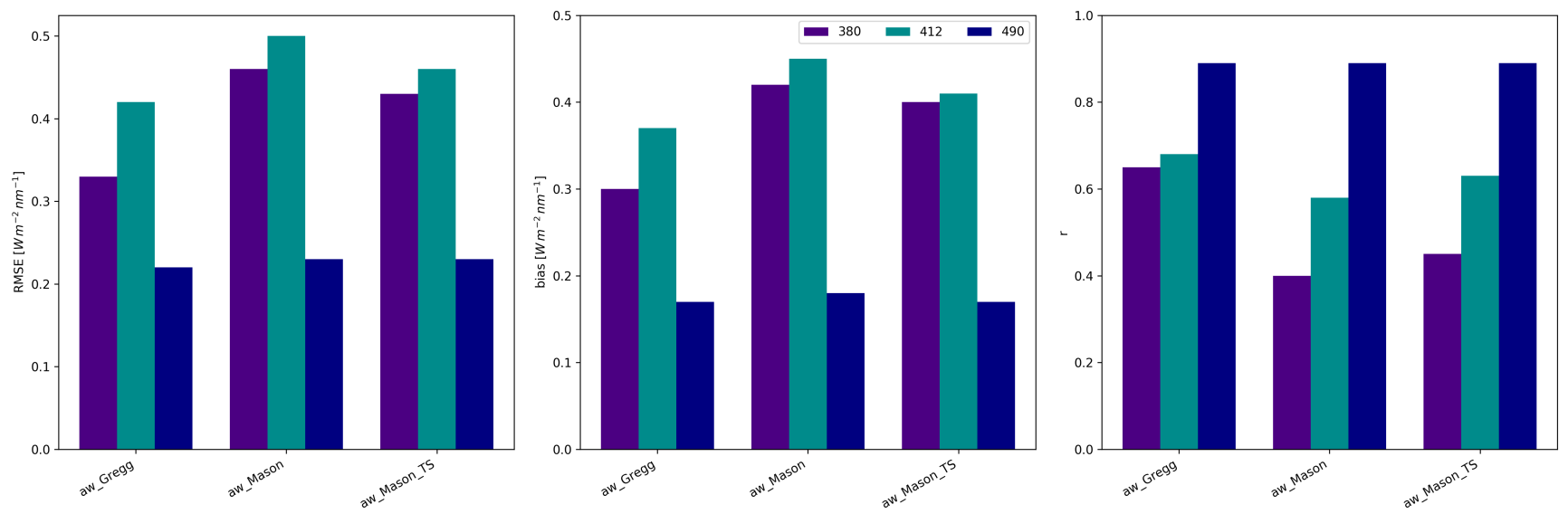

Figure 3. Skill of simulations using only pure water IOPs. The three figures (from left to right) show bias, root mean square error and Pearson correlation coefficient respectively. Each simulation type has three bar plots, representing different wavelengths (purple $380 \mathrm{~nm}$, cyan 412 $\mathrm{nm}$ and dark blue $490 \mathrm{~nm}$ ). The three types of simulations are: $a_{w}$ Gregg from the original OASIM configuration described in Gregg and Rousseaux (2016), $a_{w}$ Mason with updated absorption spectra from Mason et al. (2016) and $a_{w}$ Mason $_{T S}$ with values corrected for T and $\mathrm{S}$ of seawater. 
https://doi.org/10.5194/bg-2020-473

Preprint. Discussion started: 14 January 2021

(c) Author(s) 2021. CC BY 4.0 License.
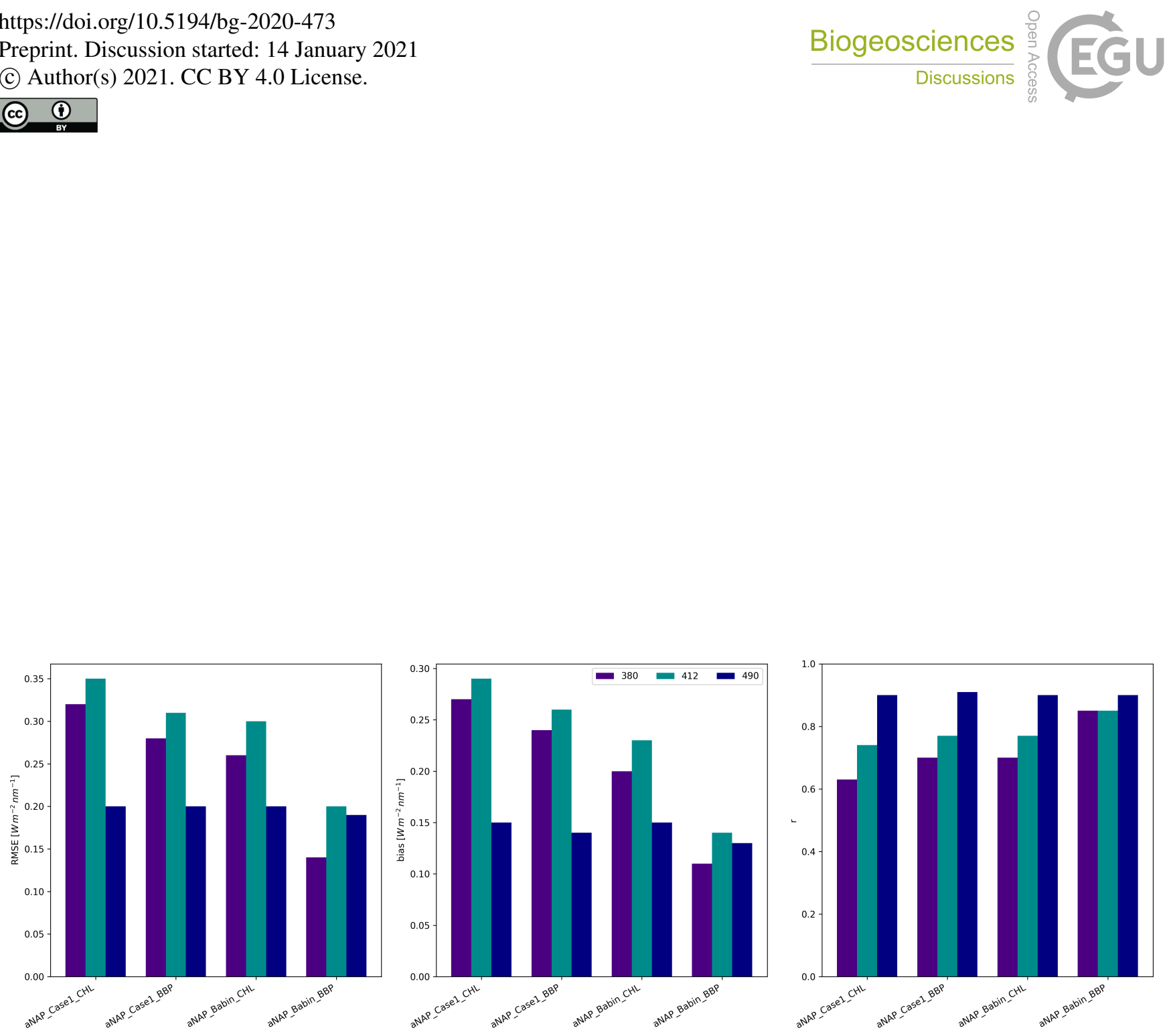

Figure 4. Skill of simulations using pure water IOPs and $a_{N A P}$. The structure of the figure follows the one in Fig.3. The four types of simulations are: two Case 1 simulations with coefficients from Bricaud et al. (2010) and two with the range of values reported in Babin et al. (2003), both alternating $\mathrm{Chl}$ and $b_{b p}(700)$ shapes. 
https://doi.org/10.5194/bg-2020-473

Preprint. Discussion started: 14 January 2021

(c) Author(s) 2021. CC BY 4.0 License.
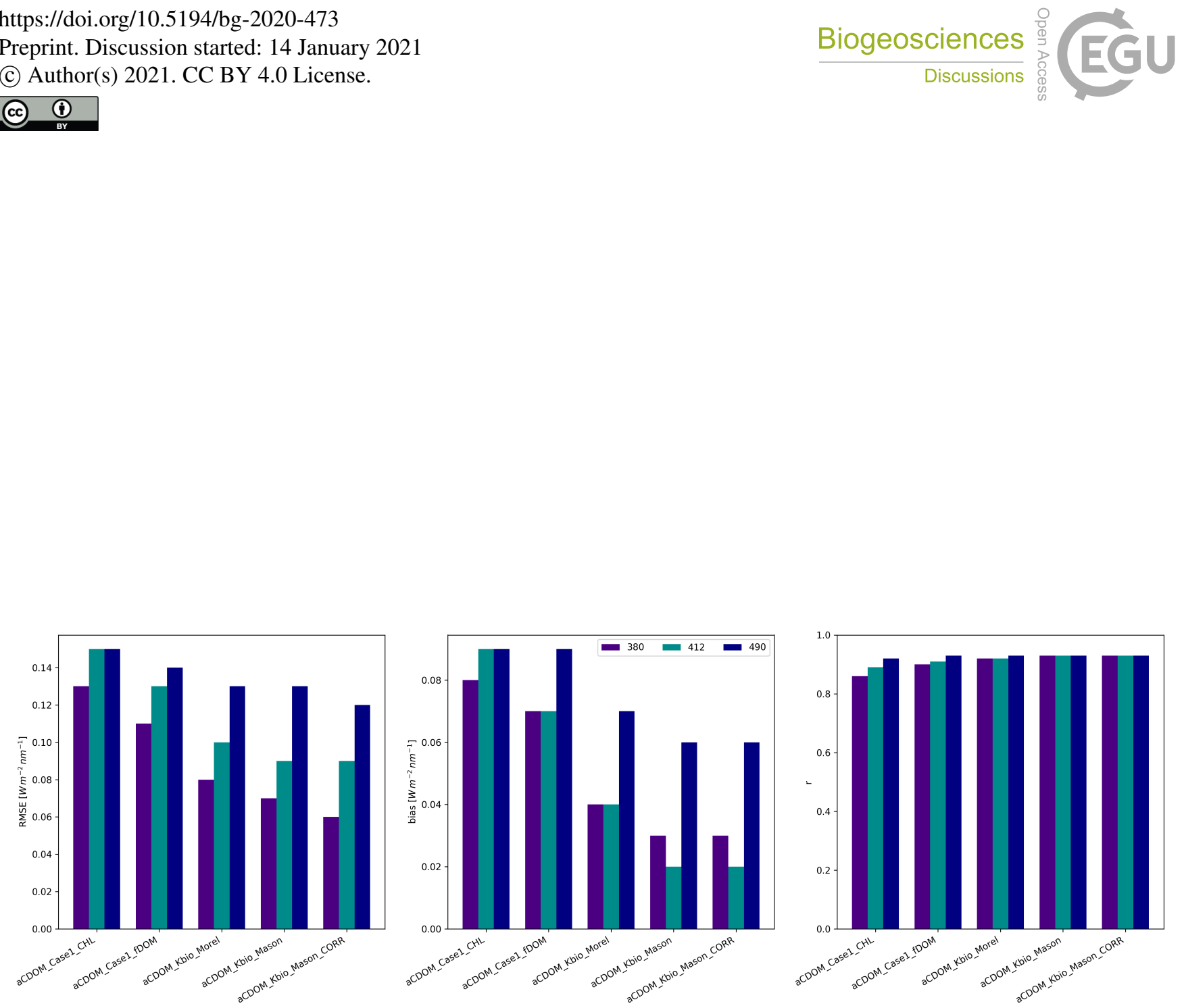

Figure 5. Skill of simulations using pure water IOPs and $a_{C D O M}$. The structure of the figure follows the one in Fig.3. The five types of simulations are: twe first two from the left are Case 1 simulations with coefficients from Morel and Gentili (2009), both alternating Chl and fDOM shapes. The other three follow the calculation of $a_{C D O M}(380)$ from $K_{b i o}(380)$ as in Organelli and Claustre (2019) and differ in the estimation of the pure water term $K_{w}$ : as a constant from Morel and Maritorena (2001) and with values of $a_{w}$ from Mason et al. (2016), with and without the correction due to $\mathrm{T}$ and $\mathrm{S}$ values. 
https://doi.org/10.5194/bg-2020-473

Preprint. Discussion started: 14 January 2021

(c) Author(s) 2021. CC BY 4.0 License.
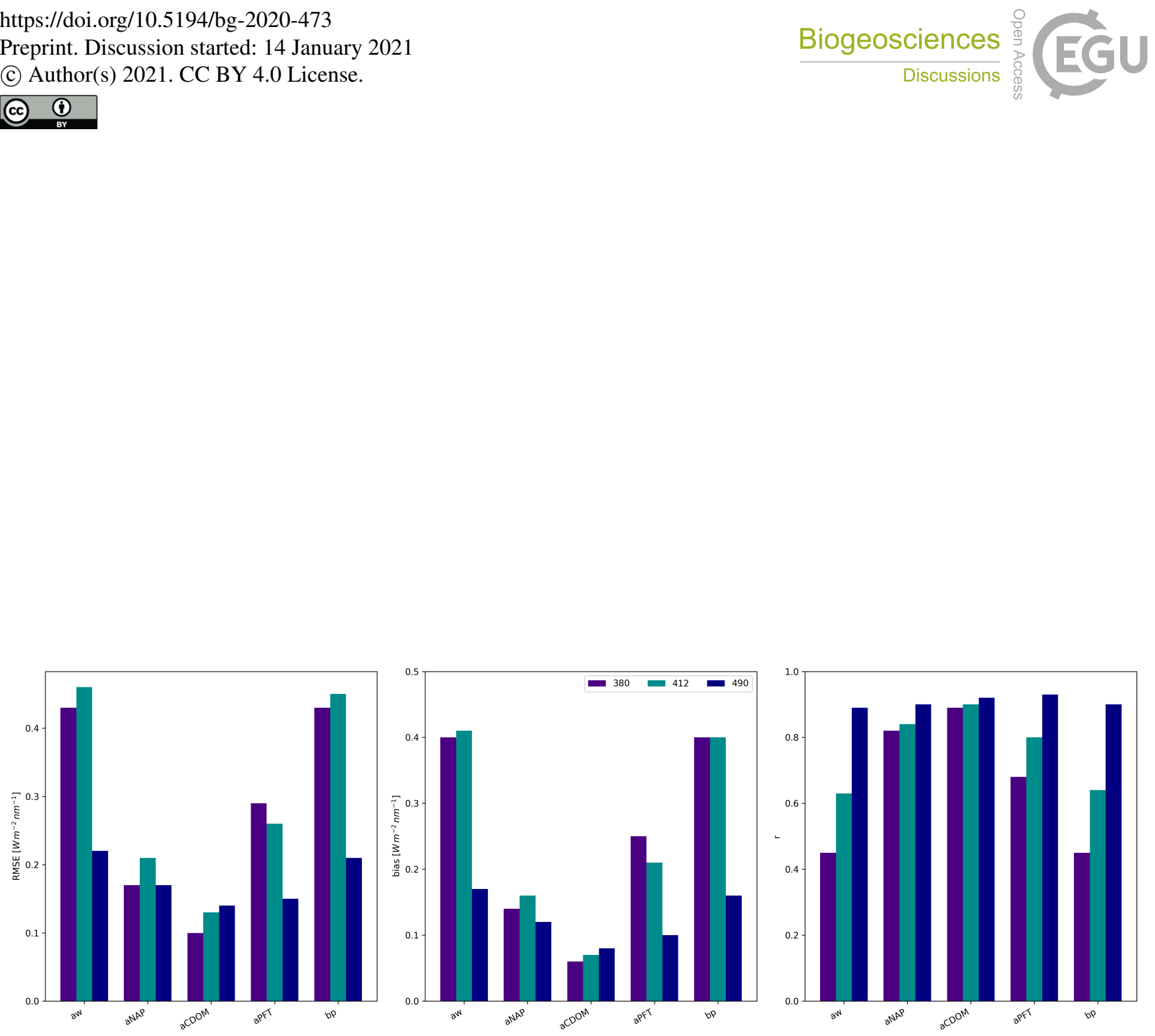

Figure 6. Skill of simulations using pure water IOPs and separate IOPs: $a_{N A P}, a_{C D O M}, a_{\phi}$ and , $b_{p}$. The structure of the figure follows the one in Fig.3. 
https://doi.org/10.5194/bg-2020-473

Preprint. Discussion started: 14 January 2021

(C) Author(s) 2021. CC BY 4.0 License.
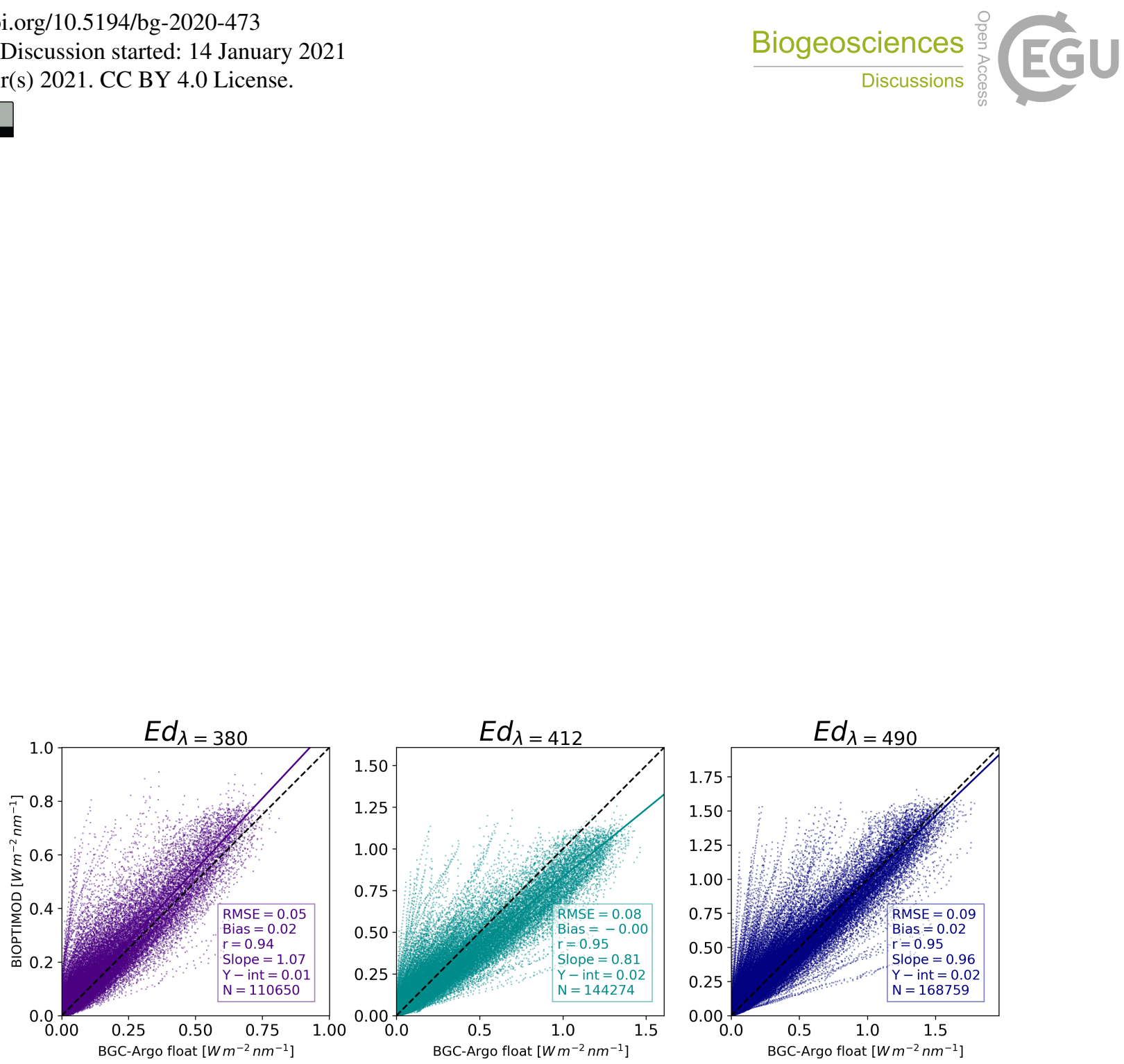

Figure 7. Match-up $E_{d}(\lambda)$ with the final modelling configuration including all IOPs in the first 150 meters, displaying the root mean square error (RMSE), bias, Pearson correlation coefficient $(r)$, slope, intercept (Y-int) and number of points (N) for each of the three wavelengths considered. 
Kd 380

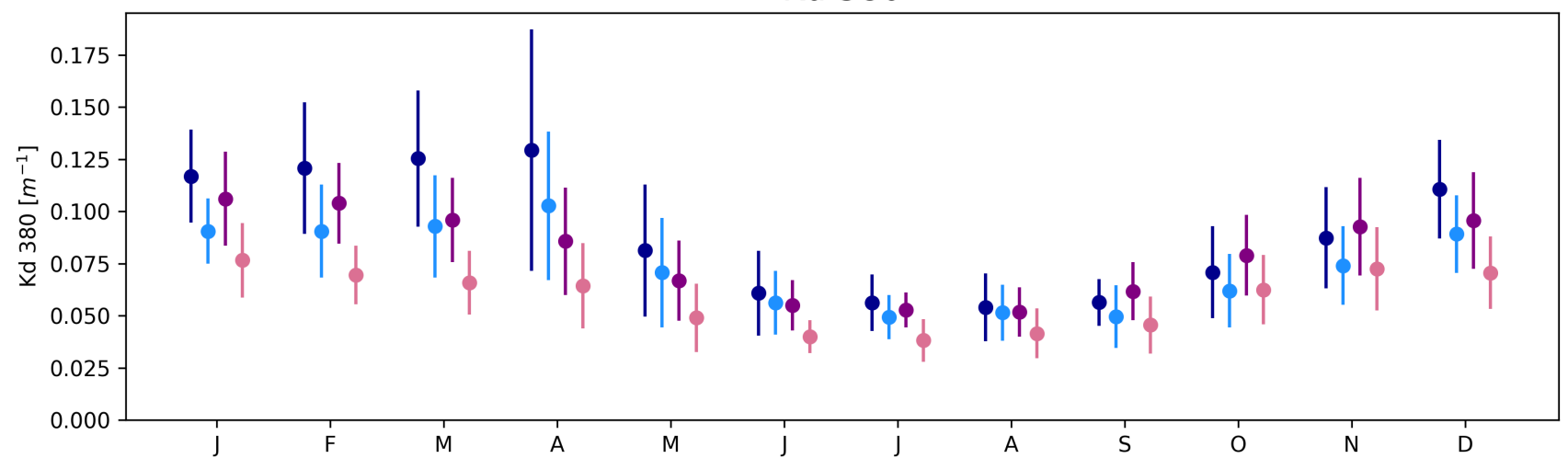

Kd 412

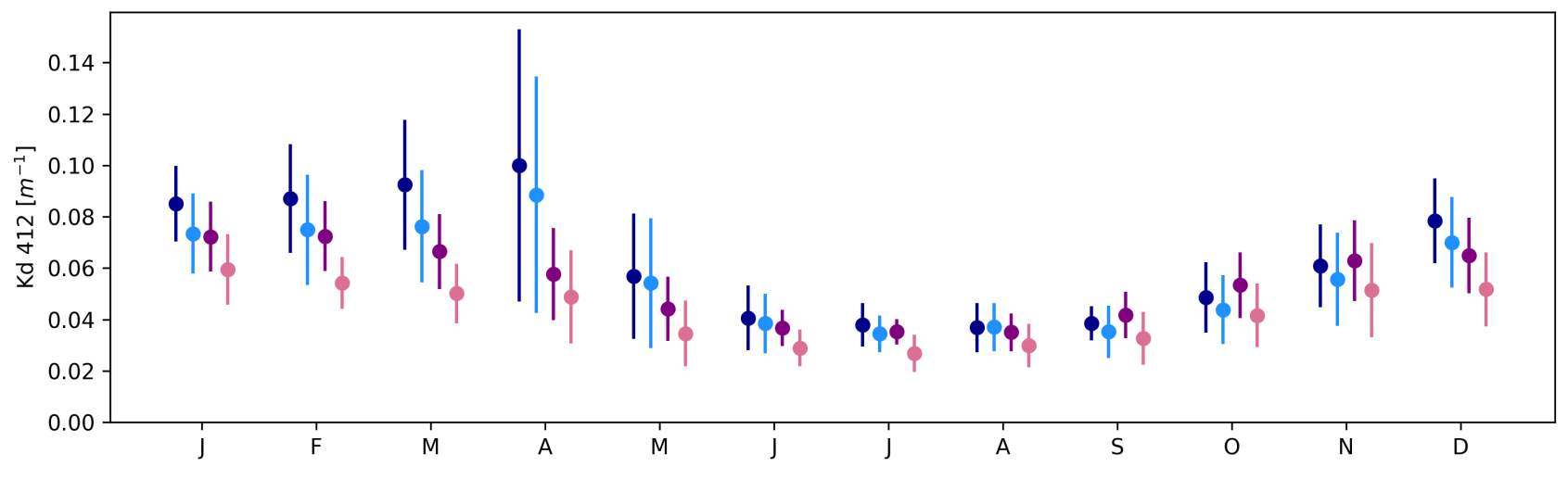

$\mathrm{Kd} 490$

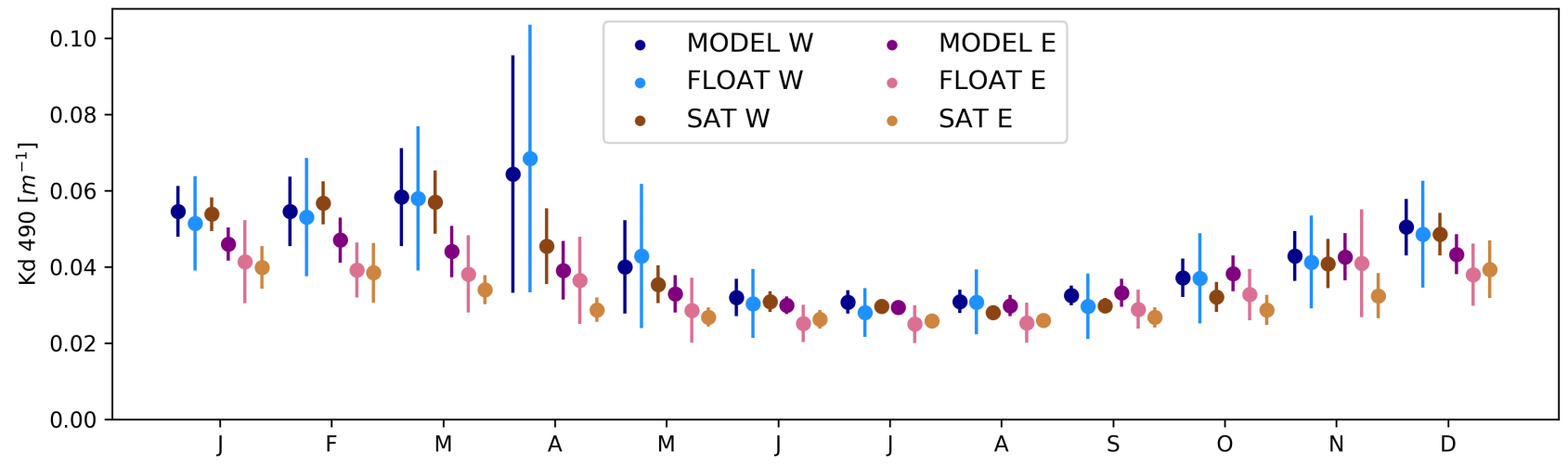

Figure 8. Match-up $K_{d}(\lambda)$ from the reference configuration. The top two figures display model (darker points) and float (lighter points) values for western (blue) and eastern (purple) basins. At $490 \mathrm{~nm}$, additional brown scatter points from satellite data are included (bottom figure). 


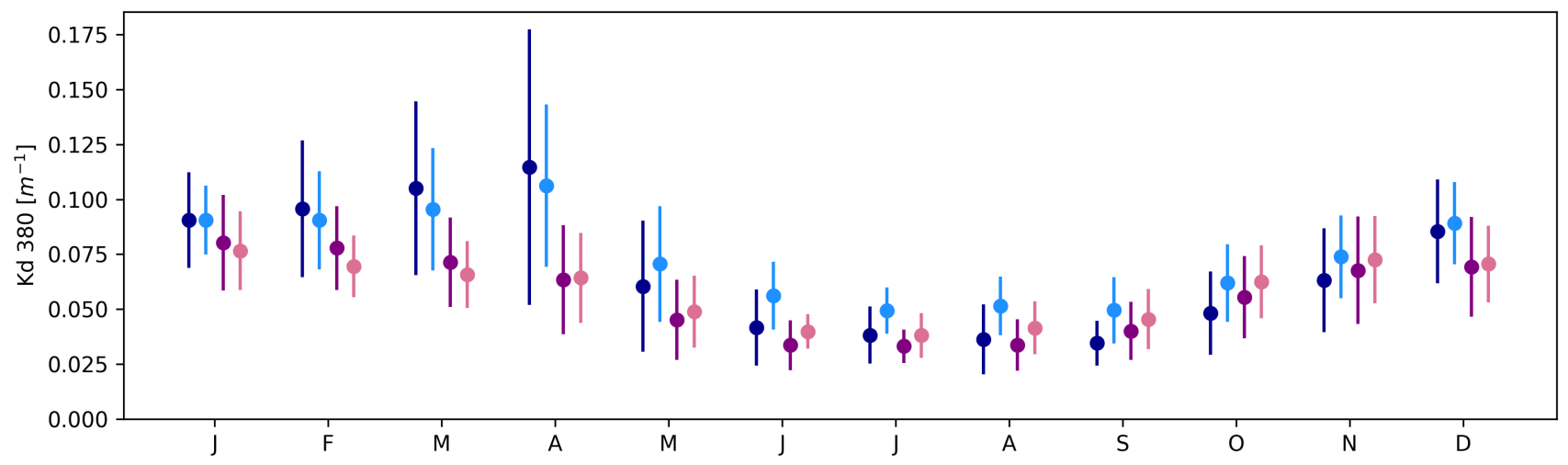

Kd 412
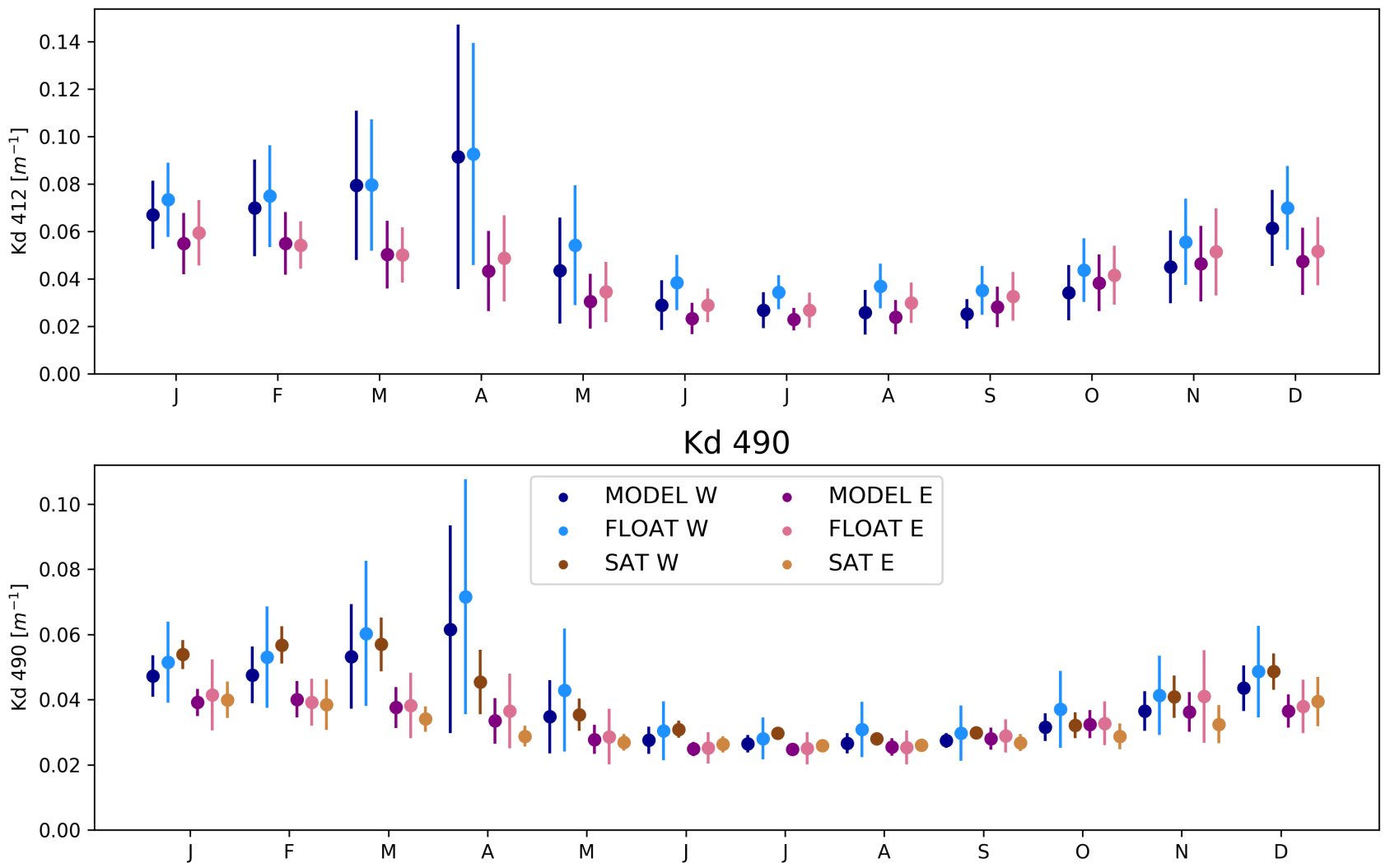

Figure 9. Match-up $K_{d}(\lambda)$ - without $a_{N A P}$. The structure of the figure follows the one in Fig.8. 
https://doi.org/10.5194/bg-2020-473

Preprint. Discussion started: 14 January 2021

(c) Author(s) 2021. CC BY 4.0 License.

$\operatorname{Rrs} 412$
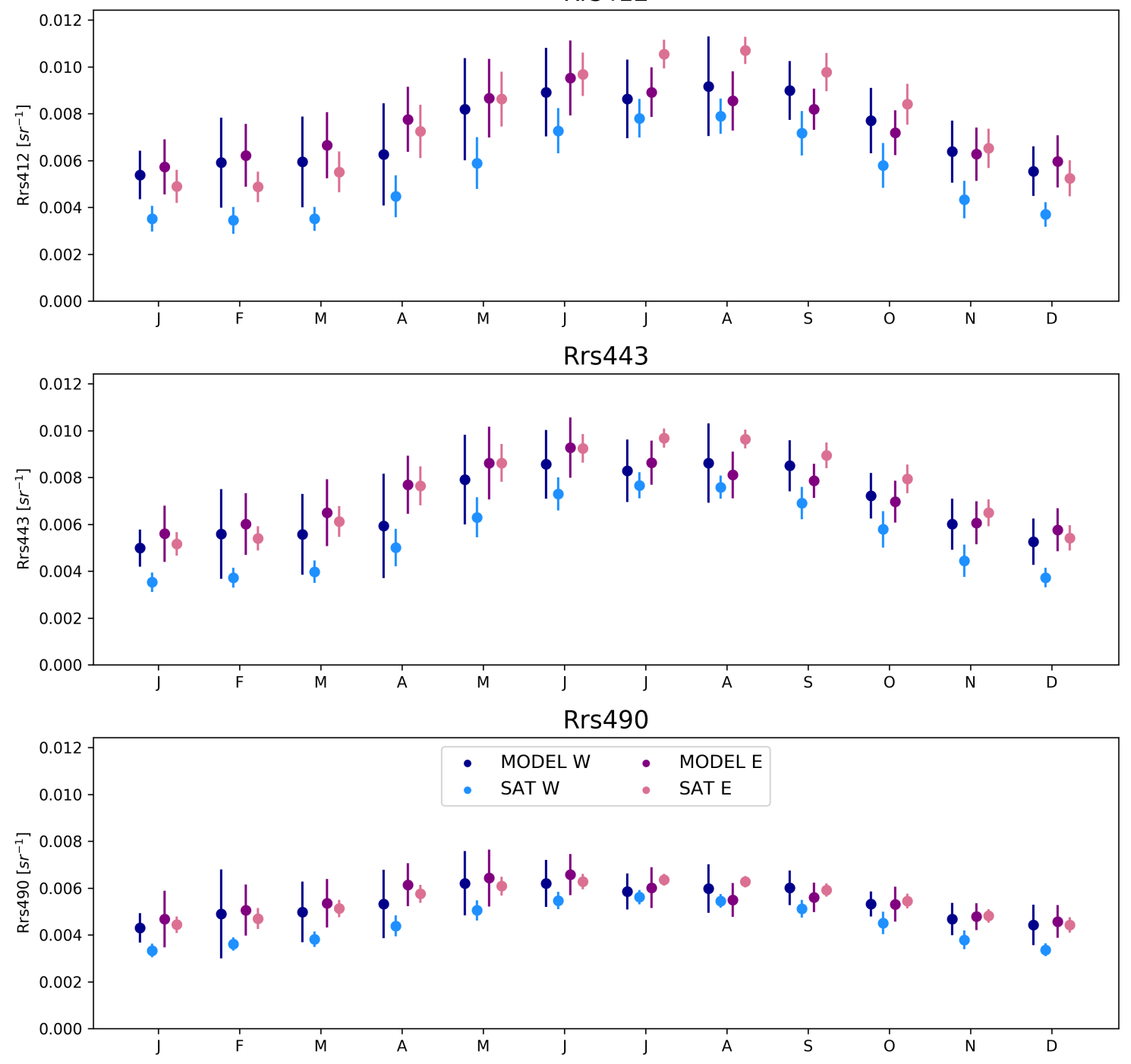

Figure 10. Match-up $R_{r s}(\lambda)$ - reference configuration. All three figures display model (darker points) and satellite (lighter points) values for western (blue) and eastern (purple) basins at 412, 443 and $490 \mathrm{~nm}$ respectively. 